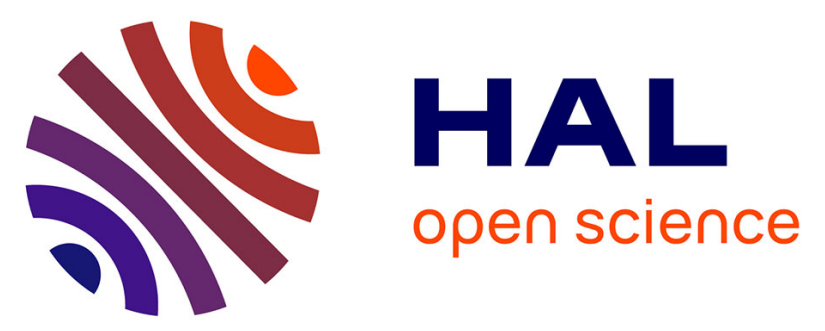

\title{
Un four de potier de l'âge du Fer pour la cuisson de pithoi à Béziers (Hérault) : production, diffusion et fonction du pithos dans le Midi (VIe-IVe s. av. J.-C.)
}

Christian Olive, Daniela Ugolini, Antoine Ratsimba, Céline Jandot, Jean-Paul Wiégant

\section{- To cite this version:}

Christian Olive, Daniela Ugolini, Antoine Ratsimba, Céline Jandot, Jean-Paul Wiégant. Un four de potier de l'âge du Fer pour la cuisson de pithoi à Béziers (Hérault): production, diffusion et fonction du pithos dans le Midi (VIe-IVe s. av. J.-C.). Gallia - Archéologie de la France antique, 2009, 66 (2), pp.29-57. 10.3406/galia.2009.3366 . hal-01898970

\section{HAL Id: hal-01898970 https://hal.science/hal-01898970}

Submitted on 19 Dec 2019

HAL is a multi-disciplinary open access archive for the deposit and dissemination of scientific research documents, whether they are published or not. The documents may come from teaching and research institutions in France or abroad, or from public or private research centers.
L'archive ouverte pluridisciplinaire HAL, est destinée au dépôt et à la diffusion de documents scientifiques de niveau recherche, publiés ou non, émanant des établissements d'enseignement et de recherche français ou étrangers, des laboratoires publics ou privés.

\section{(ㅇ)(1) $\$$}

Distributed under a Creative Commons Attribution - NonCommercial - NoDerivatives 44.0 


\title{
UN FOUR DE POTIER DE L'ÂGE DU FER POUR LA CUISSON DE PITHOI À BÉZIERS (HÉRAULT)
}

\author{
Production, diffusion et fonction du pithos dans le Midi \\ $\left(V I^{e}-I V^{e}\right.$ s. av. J.-C.)
}

\author{
Christian Olive ${ }^{1}$, Daniela UgOLINI ${ }^{2}$ et Antoine RATSIMbA ${ }^{3}$ \\ avec la collaboration de Céline JANDOT ${ }^{4}$ et Jean-Paul WIÉGANT ${ }^{5}$
}

\begin{abstract}
Mots-clés. Âge du Fer, Grecs, indigènes, four de potier, fausses voûtes, adobes, pithos, dolium, typologie, céramique, vin, bière, céréales, conservation/transformation des aliments, réserve d'eau.

Résumé. La fouille d'un grand four de potier à $3 \mathrm{~km}$ de Béziers a permis d'étudier une structure destinée à la cuisson des pithoi. Le four a fonctionné entre la fin $d u V^{e}$ s. av. J.-C. et la première moitié du IV $V^{e}$. av. J.-C. et il s'agit, semble-t-il, du seul exemplaire dévolu à cette fonction mis au jour en Méditerranée occidentale. Il était grand et, dans la chambre de chauffe, le dispositif de soutien de la lourde sole était constitué de deux piliers latéraux rejoignant un muret central par des arcs à encorbellement. Techniquement très élaboré, ce four ne peut être comparé, en Gaule, quà un autre (à amphores) découvert à Marseille.

Cet atelier si particulier confirme le rôle de producteur de céramique qu'a rempli Béziers pendant près de trois siècles et a été l'occasion de revenir sur un récipient à liquides (utilisé, entre autres, pour la vinification à Marseille comme à Béziers), mais adapté aussi à d'autres contenus. Ce vase, introduit en Gaule par les Grecs, est devenu courant en Méditerranée occidentale surtout à partir du début du IV s. av. J.-C.

Contrairement à une idée reçue, la fabrication de ces grands vaisseaux était complexe et ne pouvait se dérouler que dans des ateliers spécialisés établis près des matières premières (argile, eau, bois, sables et graviers) et à proximité d'une voie pour l'acheminement des ressources comme celui des produits finis.
\end{abstract}

Key-words. Iron Age, Greeks, indigenous, pottery kiln, false vault, adobe, pithos, dolium, typology, pottery, wine, beer, cereals, food preservation/transformation, water reserve.

Abstract. The excavation of a large pottery kiln at $3 \mathrm{~km}$ from Béziers allowed to study a structure destined for firing of pithoi. The kiln functioned between the end of the $6^{\text {th }}$ century B.C. and the first half of the $4^{\text {th }}$ century B.C.; it seems that it is the only example devoted to this function discovered in the West Mediterranean. It was large and in the fire-chamber the supporting device of the heavy hearth was constituted of two lateral pillars joining a central low wall by corbelled arches. Carefully worked out this kiln can only be compared to another one for amphorae in Gaul discovered in Marseille.

1. Ingénieur, SRA, DRAC Languedoc-Roussillon, 5 rue de la Salle-l’Évêque, CS 49020, F-34967 Montpellier Cedex 2. Courriel : christian.olive@ culture.gouv.fr

2. Chargée de recherche, Centre Camille-Jullian, UMR 6573 du CNRS, Maison méditerranéenne des sciences de l'homme, 5 rue du Château-del'Horloge, BP 647, F-13094 Aix-en-Provence Cedex 2. Courriel : dugolini@club-internet.fr

3. Archéologue contractuel Inrap, ZAC Kilomètre Delta II, 521 rue Étienne-Lenoir, F-30900 Nîmes. Courriel : antoine.ratsimba@inrap.fr

4. Chargée d'études, Inrap, Centre archéologique, 4 bis avenue Marcellin-Albert, F-66000 Perpignan. Courriel : celine.jandot@inrap.fr

5. Service archéologique de la ville de Béziers, Hôtel de Ville, place Gabriel-Péri, F-34500 Béziers. Courriel : jean-paul.wiegant@ville-beziers.fr 
So peculiar, it confirms that Béziers was a centre of pottery production during near three centuries. The opportunity is given for a review of this kind of liquid vessel (used for vinification in Massilia as in Béziers) but also suited for other contents. Introduced in Gaul by Greeks, this vase became common in western Mediterranean, mainly from the early $4^{\text {th }}$ century B.C.

The production of these large vessels, on the contrary of the generally accepted idea, was complex and made only in specialized workshops established near the spot of raw materials (clay, water, wood, sand and gravel) nearby a road for the carriage of goods and resources.

Translation: Isabelle FAUDUET

Schlüsselwörter. Einsenzeit, Griechen, Einheimische, Töpferofen, unechte Gewölbe, Lehmziegel, pithos, dolium, Typologie, Keramik, Wein, Bier, Getreide, Aufbewahrung/Verarbeitung von Lebensmitteln, Wasserreserve.

Zusammenfassung. Die Ausgrabung eines großen Töpferofens 3 km von Béziers bot die Gelegenheit, eine Struktur zu untersuchen, die dem Brennen von pithoi diente. Der Ofen war zwischen dem Ende des 6. Jh. v. Chr. und der ersten Hälfte des 4. Jh. v. Chr. in Betrieb. Es scheint sich um den einzigen Ofen mit dieser Funktion zu handeln, der im westlichen Mittelmeerraum freigelegt wurde. Der Ofen war groß, die schwere Sohle wurde in der Feuerkammer durch eine Vorrichtung aus zwei seitlichen, durch Kragbogen mit einem zentralen Stützmäuerchen verbundene Pfeiler gestützt. Für diesen technisch sehr ausgefeilten Ofen gibt es in Gallien nur eine Parallele in Marseille (in diesem Ofen wurden Amphoren gebrannt).

Diese so ungewöhnliche Werkstatt bestätigt die Rolle, die Béziers drei Jahrhunderte lang in der Keramikproduktion gespielt hat, und bietet zudem Gelegenheit auf einen für Flüssigkeiten bestimmten Gefäßtyp zurückzukommen (sowohl in Marseille als auch in Béziers diente er u.a. der Weinbereitung), der sich jedoch ebenfalls für andere Inhalte eignete. Dieser Gefäßtyp wurde in Gallien von den Griechen eingeführt und wurde im westlichen Mittelmeerraum vor allem ab dem Beginn des 4. Jh. v. Chr. geläufig. Entgegen einer weit verbreiteten Vorstellung war die Herstellung dieser großen Gefäße komplex und konnte nur in spezialisierten Werkstätten in der Nähe der Rohstoffuorkommen (Ton, Wasser, Holz, Sand und Kies) stattfinden. Die Ateliers lagen darüber hinaus in der Nähe eines Verkehrsweges, der ebenso der Beförderung der Rohstoffe als auch der Fertigprodukte diente.

Übersetzung: Isa ODENHARDT-DONVEZ

En 1986, un four de potier a été découvert place de la Madeleine, dans le centre-ville de Béziers. Il faisait partie d'un complexe qui a fonctionné jusqu'au début du $\mathrm{V}^{\mathrm{e}} \mathrm{s}$. av. J.-C. et qui comprenait au moins un deuxième four (qui n'a pas pu être fouillé) et diverses fosses remplies de sables calibrés. Cet atelier a produit diverses classes de vaisselle tournée. Il y a vingt ans, cet atelier était le seul connu dans le Midi de la France pour une date aussi ancienne, même si d'autres lieux de productions tournées avaient été pressentis, voire mis en évidence ailleurs, et notamment à Marseille. Devant l'importance de la découverte, ce four, d'un type conforme aux pratiques grecques contemporaines et présentant néanmoins une certaine originalité, a été publié, ainsi que les autres productions de l'atelier, dans cette revue (Ugolini, Olive, 1987-1988).

La découverte, dans la périphérie immédiate de Béziers (fig. 1), d'un nouveau four de potier, cette fois-ci dévolu à la cuisson de pithoi manufacturés sur place, confirme le rôle de centre producteur qu'a joué ce site durant l'âge du Fer et la capacité des potiers biterrois à mettre en œuvre des technologies très avancées pour l'époque.

Au vu de l'intérêt que peuvent susciter les données liées à ce nouvel atelier, nous proposons cette étude dans la continuité de la découverte de 1986.

\section{GIRCONSTANCES DE LA DÉCOUVERTE}

La Société d'équipement du Biterrois et de son littoral (SEBLi) envisageait d'aménager une vingtaine d'hectares de terrains agricoles en bordure de la route de Bessan (RD 28), au lieu-dit Bailheron situé à $3 \mathrm{~km}$ à l'est du centreville ${ }^{6}$.

Ce secteur longe l'axe qui sera plus tard celui de la voie Domitienne et il est connu de longue date pour la richesse et le nombre de vestiges concernant l'époque romaine. Cela a motivé la prescription d'un diagnostic archéologique préalable aux travaux d'aménagement qui a été réalisé par une équipe de l'Afan (Association pour les fouilles archéologiques nationales), sous la direction de Céline Jandot.

Plusieurs sites archéologiques ont été repérés à cette occasion : une fosse du Néolithique ancien, deux fosses et deux fours à pierres chauffantes (ou fours dits polynésiens) du Néolithique final et, surtout, est apparue, sur la pente orientale de la colline, sur près de 3 ha, une occupation

6. Les parcelles aménagées sont comprises dans une ZAC nommée La Domitienne, celle incluant le four de potier est cadastrée sous le $\mathrm{n}^{\circ} \mathrm{DN}$ 130. Le lieu-dit cadastral est toujours Bailheron, mais l'appellation courante est désormais La Domitienne, c'est donc le nom que nous retenons pour le lieu de découverte du four. 


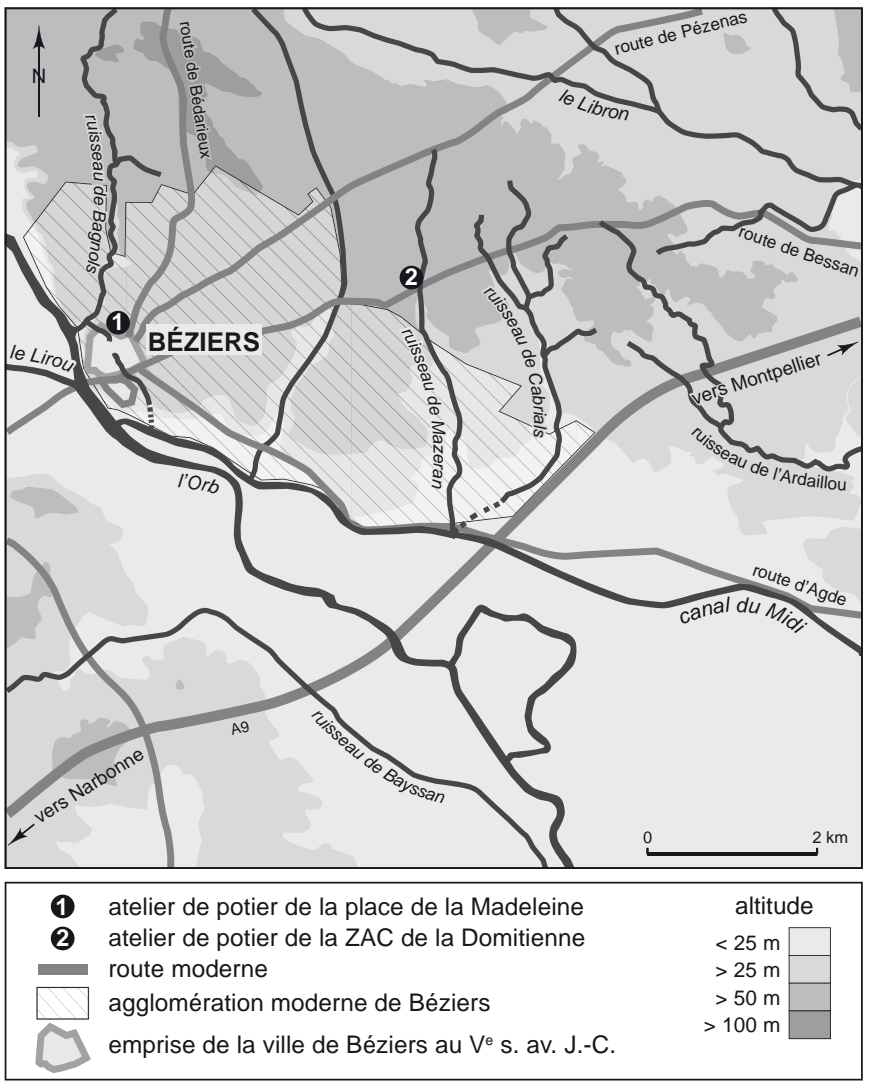

Fig. 1 - Carte de la zone de Béziers et de la basse plaine de l'Orb (carte: C. Olive, SRA Languedoc-Roussillon).

assez dense de l'âge du Bronze (fossés, fosses, céramiques, faune, etc.).

Le four de potier de l'âge du Fer a été mis au jour au bas de la colline, en bordure du ruisseau de Mazeran.

Des traces de mise en culture d'époque romaine (fossés, petit étang, bâti) ont été retrouvées sur la pente occidentale. Un fossé bordier de la voie Domitienne a également été identifié (Jandot, 2000 ; Jandot et al., 2000).

Les vestiges du four de potier se trouvaient à $0,95 \mathrm{~m}$ de profondeur par rapport à la surface du terrain actuel, dans la tranchée $\mathrm{n}^{\circ} 10 \mathrm{du}$ diagnostic, et ont été enregistrés sous le sigle FR 1009 (fig. 2). Un dégagement partiel et la fouille d'un quart de la chambre de chauffe ont permis de le dater de l'âge du Fer (un test a été effectué dans la chambre de chauffe afin d'évaluer son état de conservation et sa datation). Aucun autre vestige contemporain n'est apparu dans les sondages périphériques. Toutefois, lors de la fouille de la voie Domitienne, située à une cinquantaine de mètres au sud, plusieurs couches archéologiques en place ont été fouillées et pourraient être contemporaines de l'activité du four. Ces niveaux ont été observés

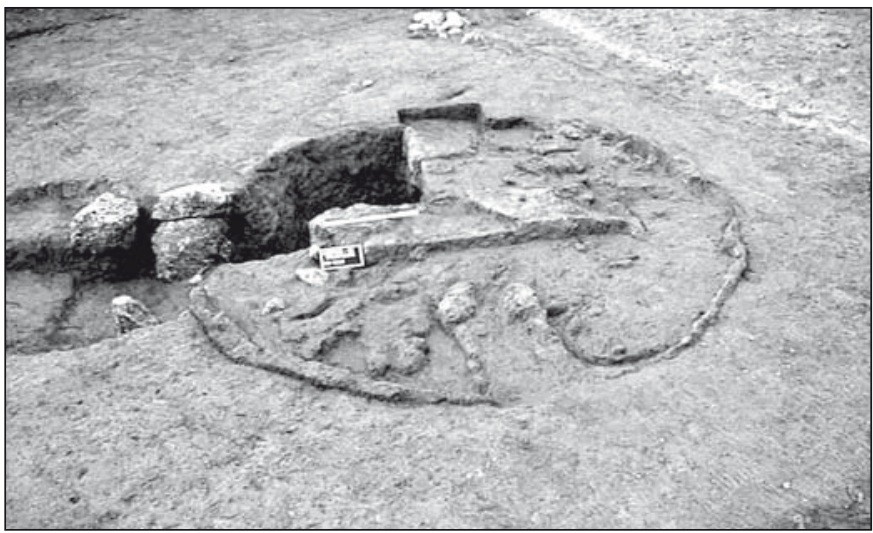

Fig. 2 - Le four de potier lors de sa découverte (cliché : C. Olive, SRA Languedoc-Roussillon).

dans plusieurs sondages, notamment dans celui pratiqué sous la chaussée romaine de la voie Domitienne, et contenaient des fragments d'amphores massaliètes, d'amphores étrusques, de céramiques à pâte claire et non tournée. Ces niveaux de circulation sont datés entre 500 et 300 av. J.-C. (Jandot, Gomez et al., 2003, p. 27). D’autre part, on a noté la présence de nombreux fragments de l'âge du Fer dans les couches d'un établissement rural romain adjacent (céramiques grises monochromes, amphores massaliètes, pithoi, etc.), montrant les remaniements des niveaux anciens dès le Haut-Empire.

Bien que le four ait été situé dans un secteur qui ne devait pas être affecté par les travaux d'aménagement, l'intérêt scientifique qu'il représentait, en liaison directe avec les problématiques concernant la première ville de Béziers, nous a conduit à envisager sa fouille en accord avec l'aménageur ${ }^{7}$ (Olive et al., 2001 ; Ugolini, 2005, fig. 5 ; Ugolini, à paraître a).

\section{L'ENVIRONNEMENT GÉOLOGIQUE}

La zone explorée est située dans une petite vallée alluviale bordée de marnes, en bordure immédiate du ruisseau de Mazeran, qui coule actuellement dans un lit

7. L'intervention s'est déroulée durant le mois de janvier 2001. L'équipe de fouille était composée de C. Olive, D. Ugolini, C. Jandot, J.-P. Wiégant, J. Cassignol et L. Rodriguez. Nous tenons à remercier MM. Raymond Couderc (sénateur-maire de Béziers) et Henri Dorne (directeur de la Société d'équipement du Biterrois et de son littoral) pour leur aide et leur appui. Le four de potier a été moulé et reproduit à l'identique grâce à des subventions de l'État, de la ville de Béziers et du supermarché Super U. Le moulage est exposé au Musée du Biterrois. Les structures fouillées sont toujours en place et conservées sous une aire de stationnement. 
étroit et encaissé (fig. 1). La vallée qu'il parcourt est recouverte d'une puissante couche de sédiments marno-argileux provenant du dépôt d'alluvions. Le ruisseau présente un régime suffisamment soutenu pour qu'un pont ait été construit à l'époque romaine pour son franchissement par la voie Domitienne et pour que des travaux importants de drainage et de canalisation aient été réalisés ces dernières années. Les basses collines qui émergent de part et d'autre sont constituées d'argile et de couches de conglomérat calcaire. Jusqu'à une date récente, ces terres étaient cultivées en vigne, céréales et jardins.

L'aspect de cette zone a été profondément modifié par les aménagements de la ZAC (déblais/remblais) et par la construction de plates-formes commerciales (fig. 3).

\section{LES VESTIGES DÉCOUVERTS}

Un décapage de plus de $200 \mathrm{~m}^{2}$ entre les tranchées ouvertes auparavant pour les besoins du diagnostic archéologique a été réalisé à la pelle mécanique dans la zone du four, sous le niveau des labours (à $0,95 \mathrm{~m}$ de profondeur), afin de prendre en compte autant que possible l'ensemble de l'environnement (fig. 3).

Plusieurs vestiges de différentes époques ont été mis au jour :

- au sud-est de la zone explorée, des vestiges gallo-romains très arasés (murs, sols, fosses) ;

- au nord de la zone décapée, se trouve le four de potier de l'âge du Fer, dont l'accès à l'alandier est pourvu d'une vaste fosse. Cet ensemble était assez bien conservé. Aucun autre élément lié au fonctionnement de l'atelier de potier n'a été retrouvé car le niveau de circulation contemporain a été détruit par les travaux agricoles et les aménagements gallo-romains.

L'aire décapée présentant des vestiges de deux périodes chronologiquement bien distinctes, la fouille a été divisée en deux secteurs : le secteur sud-est (phase gallo-romaine) et le secteur nord-ouest (atelier de potier) ${ }^{8}$.

Toutes les structures ont été construites sur, ou dans, un même sédiment marno-argileux marron, qui forme le substratum, où les différences de couleur entre les creusements et les comblements sont parfois très difficiles à identifier.

8. Les numéros des structures repérées lors du diagnostic ont été conservés : fosse FS 1006, mur MR 1007, tranchée TR 1008 (d'époque romaine) et four FR 1009 (âge du Fer). Les unités stratigraphiques fouillées lors de cette nouvelle opération ont été numérotées à partir de 1100 .

\section{LE FOUR DE POTIER}

La fouille du secteur nord-ouest a mis au jour un grand four de potier, conservé juste sous le niveau de la sole, et sa fosse d'alimentation (fig. 4). Les décapages périphériques n'ont pas permis de retrouver les autres aménagements de l'atelier, car on se trouve sous les niveaux de circulation contemporains du fonctionnement de l'atelier.

\section{LA CHAMBRE DE CHAUFFE}

La chambre de chauffe était constituée d'une grande fosse subcirculaire de 2,65 $\mathrm{m}$ de diamètre, conservée sur 0,84 m de hauteur, creusée dans le substrat argilo-marneux et dont le fond était à peu près horizontal et régulier (fig. $5 \mathrm{a}$ et b). Elle communiquait avec la fosse d'alimentation par un alandier, au sud-ouest. Tous les aménagements intérieurs avaient été soigneusement recouverts d'une couche d'argile très plastique, rubéfiée par la chaleur. Le creusement de la chambre de chauffe a recoupé une fosse néolithique (attribuable au Vérazien), de forme ovale et peu profonde, qui contenait deux grands vases modelés, emboîtés l'un dans l'autre (fig. 6).

Trois supports bâtis étaient disposés sur le fond et contre les parois pour soutenir la sole. Un mur coupait la chambre de chauffe en deux parties égales dans l'axe de l'alandier (fig. 7). Large de 0,43 $\mathrm{m}$ et long de 1,52 $\mathrm{m}$ hors tout (enduit compris), il reposait sur le sol et était construit en adobes, identifiables sous le revêtement d'argile cuite et durcie. Les briques d'argile crue (cuites et durcies par la chaleur) ont été employées soit entières, soit découpées. Celles qui étaient entières présentaient des dimensions constantes : $0,45 \mathrm{~m}$ à $0,46 \mathrm{~m}$ de longueur sur $0,38 \mathrm{~m}$ à $0,39 \mathrm{~m}$ de largeur pour $0,07 \mathrm{~m}$ à $0,075 \mathrm{~m}$ d'épaisseur.

Les extrémités de ce mur présentaient des départs de fausses voûtes appuyées, au nord-est, sur la paroi arrière de la chambre de chauffe et, au sud-ouest, au-dessus de l'alandier. Ces fausses voûtes étaient réalisées par le décalage successif des briques employées dans la construction, de manière à former un encorbellement régulier permettant de rattraper les espaces laissés libres pour la circulation de la chaleur : elles se développaient sur 0,30 m à l'arrière du four et sur 0,60 m à l'avant.

De part et d'autre du mur central, deux piliers complétaient le dispositif de support de la sole : ils étaient également en adobes et étaient accolés à la paroi de la chambre de chauffe, en léger débord de 0,30 m pour le pilier nord-ouest et de $0,35 \mathrm{~m}$ pour le pilier sud-est. Ils présentaient un encor- 

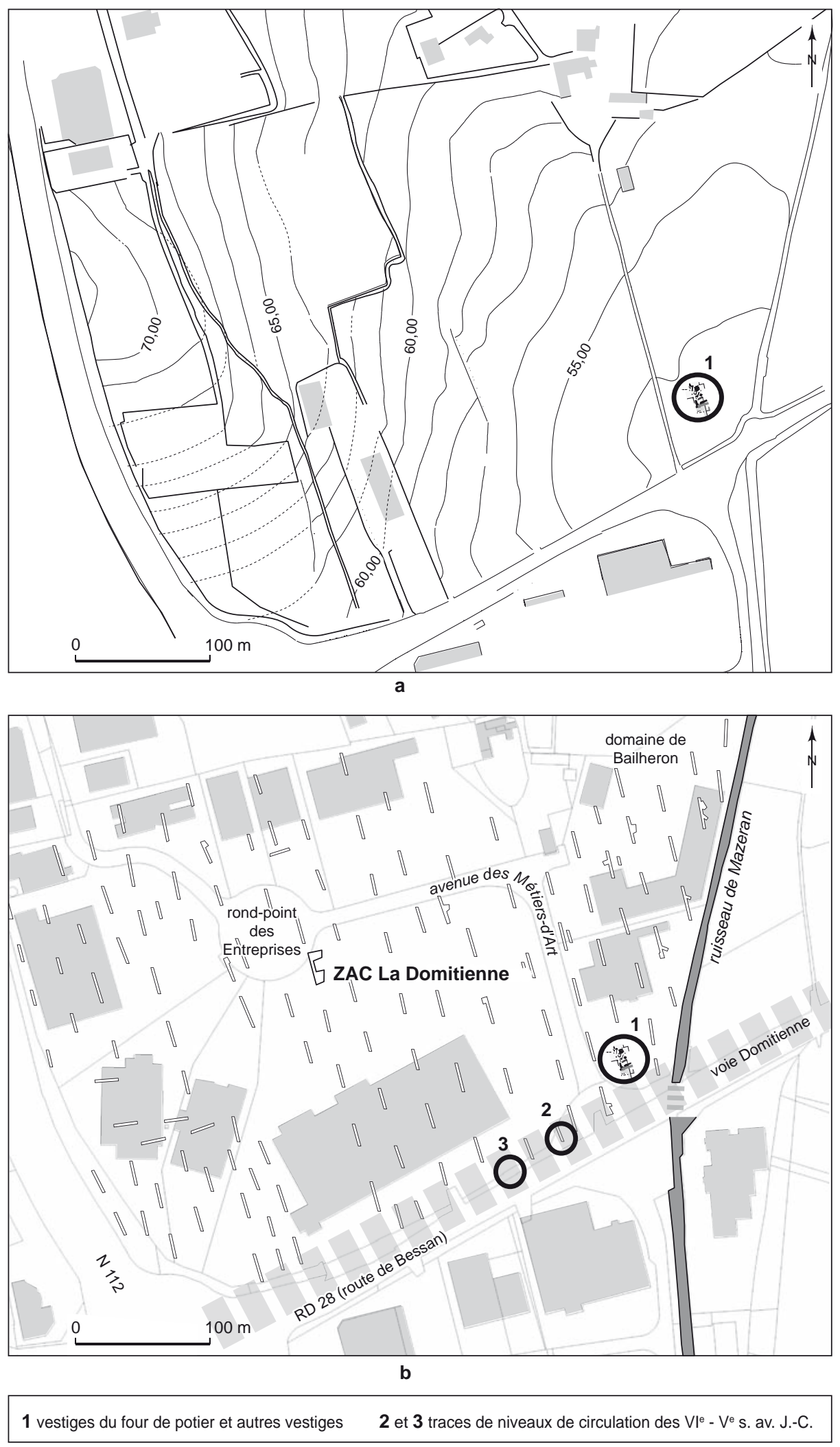

Fig. 3 - a, plan cadastral et courbes de niveau du lieu-dit Bailheron avant les aménagements de la ZAC de la Domitienne; b, plan de la ZAC de la Domitienne et situation des tranchées archéologiques de diagnostic (DAO : a, C. Olive, SRA LanguedocRoussillon; b, F. Audouit et S. Barbey, Inrap). 


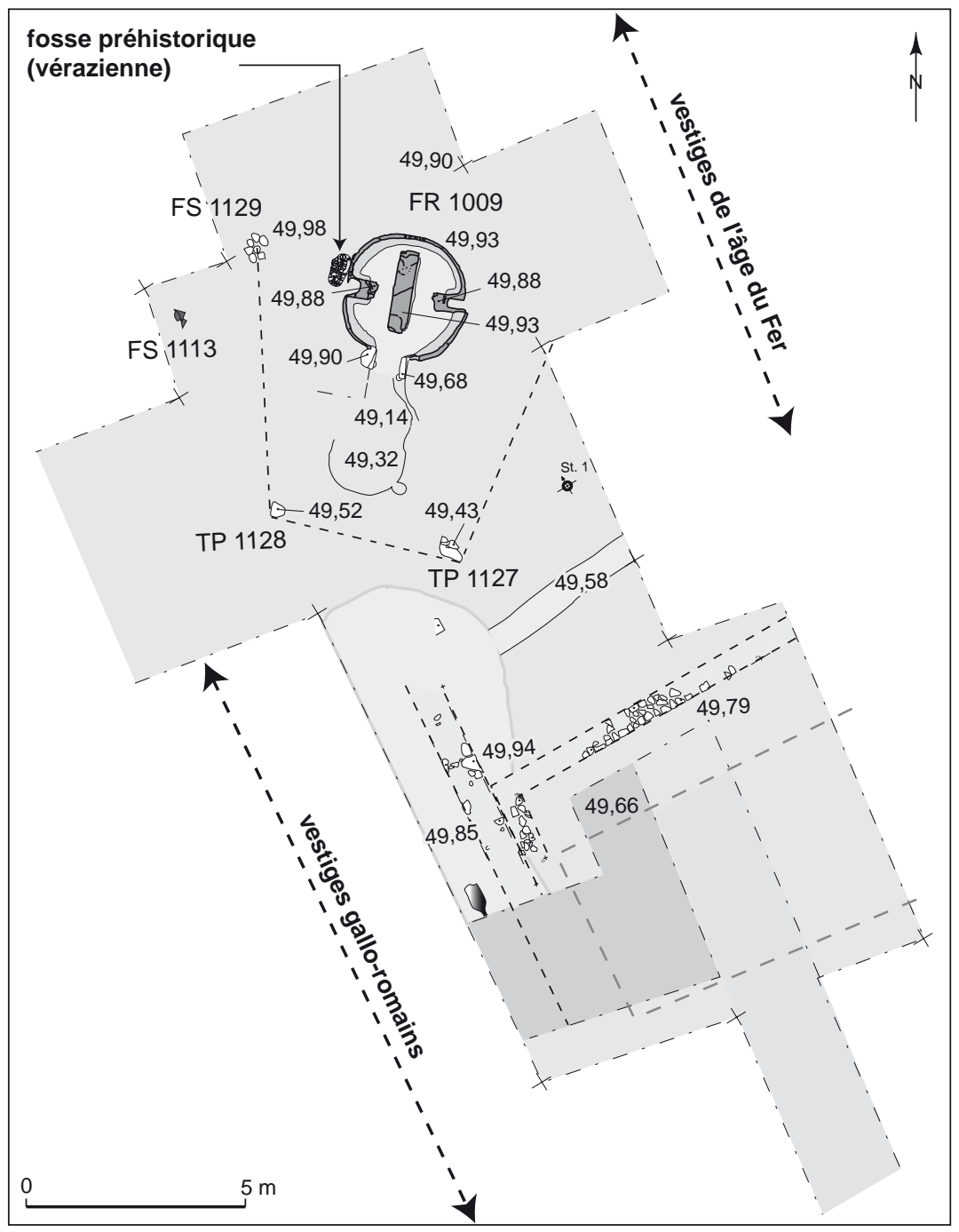

Fig. 4 - Plan général des vestiges mis au jour : au nord, four de potier de l'âge du Fer dont l'installation a coupé une fosse néolithique (époque vérazienne), au nord-ouest. Des niveaux gallo-romains, partiellement conservés au sud, ont ensuite recouvert les phases d'occupation plus anciennes ; FS, fosse; FR, four ; TP, trou de poteau (DAO : C. Olive, D. Ugolini et J. Cassignol).

bellement d'adobes formant une fausse voûte appuyée au pilier central. Ainsi, l'espace laissé libre pour la circulation de l'air chaud était large d'environ 0,70 m.

Comme pour les parois de la chambre de chauffe, toutes les faces des piliers en adobes étaient recouvertes d'une couche d'argile fine, qui a été rubéfiée par la chaleur. Ce revêtement a été observé sur une épaisseur de $0,08 \mathrm{~m}$ à $0,15 \mathrm{~m}$ sur la paroi de la chambre de chauffe et sur $0,03 \mathrm{~m}$ sur les piliers d'adobes.

La partie du four en contact avec le comblement de la fosse néolithique, qui était située en bordure de la paroi nord de la chambre de chauffe, était fragilisée. Des effritements se sont produits pendant la période de fonction- nement du four : on a observé ici de multiples réparations consistant en des applications successives d'un revêtement d'argile. Ces reprises, qui ont dû être souvent nécessaires durant les années de fonctionnement du four, expliquent la présence de quelques tessons préhistoriques dans le comblement du four.

\section{LA SOLE}

Des fragments de la sole ont été recueillis dans le comblement $\mathrm{du}$ four et dans les niveaux bouleversés. Ils permettent de restituer ses principales caractéristiques (fig. 8, $\mathrm{n}^{\text {os }}$ 1-8 et fig. 9). 


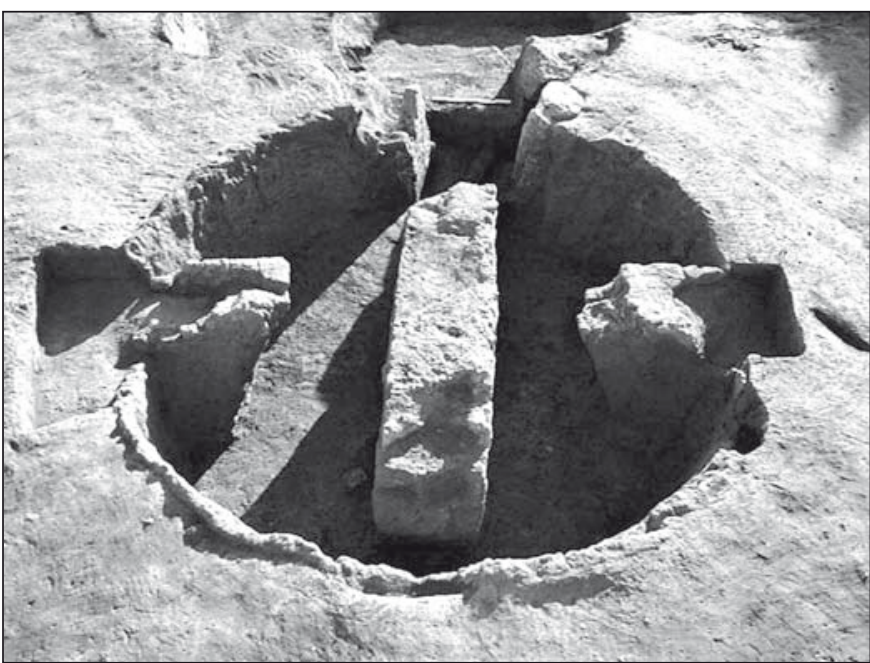

a

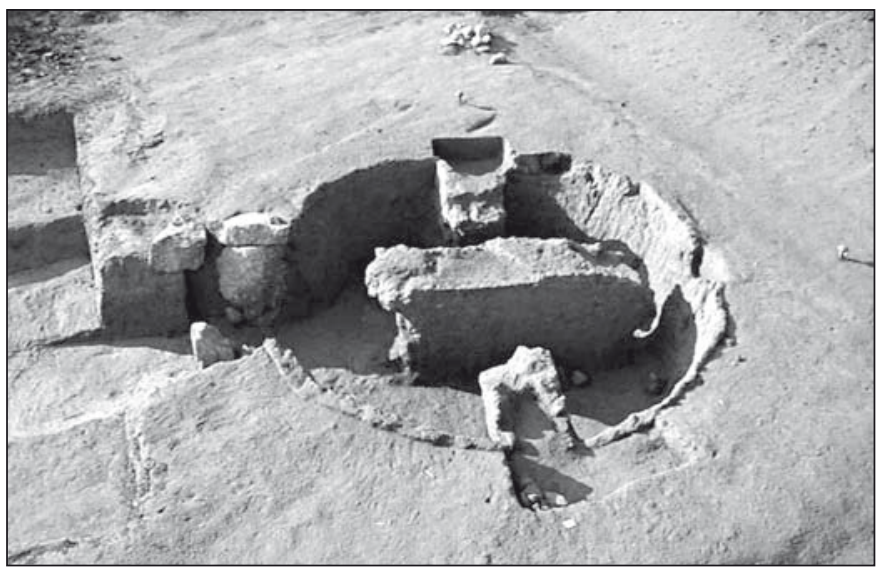

b

Fig. 5 - La chambre de chauffe du four de potier (clichés : C. Olive, SRA Languedoc-Roussillon).

La sole, en argile mélangée d'un dégraissant relativement fin de sable et de tout petits graviers, était perforée de trous circulaires d'un diamètre de $6 \mathrm{~cm}$ à $6,5 \mathrm{~cm}$ permettant le passage de la chaleur. Elle devait être moulée en une seule pièce épaisse d'au moins $15,5 \mathrm{~cm}$ à $16 \mathrm{~cm}$ et épousait la forme de la chambre de chauffe sur laquelle elle était vraisemblablement posée et fixée. Son poids, sans doute considérable, était supporté par le mur/pilier central et les supports latéraux de la chambre de chauffe.

\section{L'ALANDIER}

L'alandier était large de $0,60 \mathrm{~m}$ et long de $0,50 \mathrm{~m}$. Son sol, dans la continuité de celui de la chambre de chauffe, était régulier et également recouvert d'argile rubéfiée.

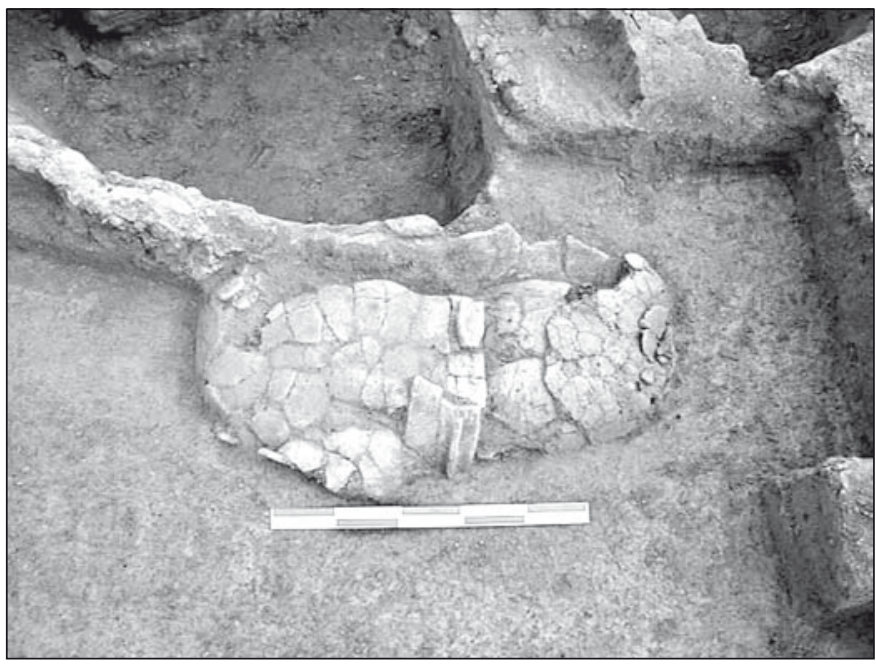

Fig. 6 - Fosse du Néolithique final, recoupée par le creusement de la chambre de chauffe du four de potier qui contenait deux vases emboîtés dont la forme est typique de la culture vérazienne (cliché: C. Olive, SRA Languedoc-Roussillon).

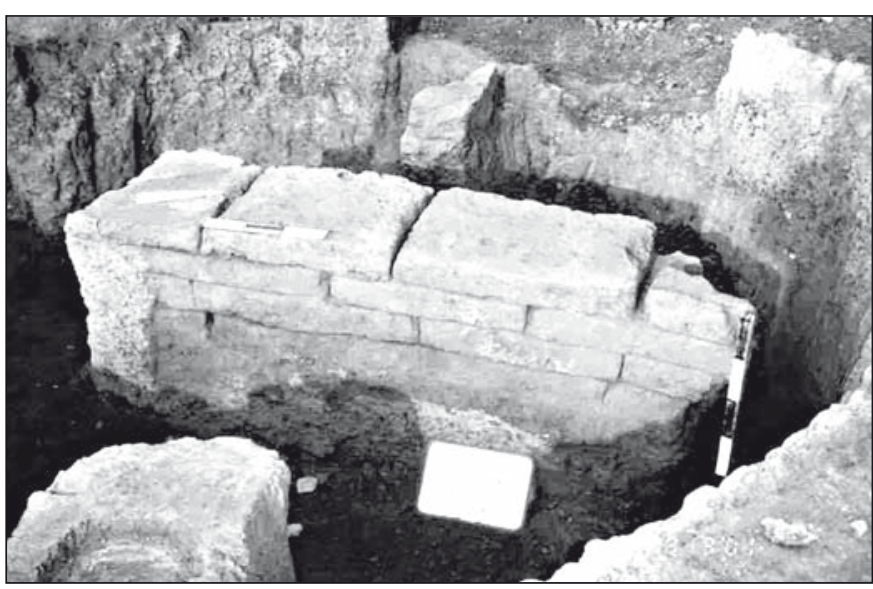

Fig. 7 - Le support central en adobes après enlèvement du revêtement argileux $(3 \mathrm{~cm})$, montrant l'agencement initial des briques d'argile crue qui ont été cuites et solidifiées par la chaleur (cliché : C. Olive, SRA Languedoc-Roussillon).

Ses parois étaient constituées de gros blocs de calcaire : $\mathrm{au}$ sud-est, une grosse dalle en calcaire (de $0,50 \mathrm{~m}$ de longueur, 0,40 $\mathrm{m}$ de hauteur et 0,12 $\mathrm{m}$ d'épaisseur) était disposée de chant, de manière à constituer un encadrement régulier. $\mathrm{Au}$ nord-ouest, deux blocs en calcaire étaient superposés : leur face lisse formait, pour ce côté aussi, une paroi régulière (fig. 5b).

Aucune trace de la partie supérieure de l'alandier n’a été retrouvée. 

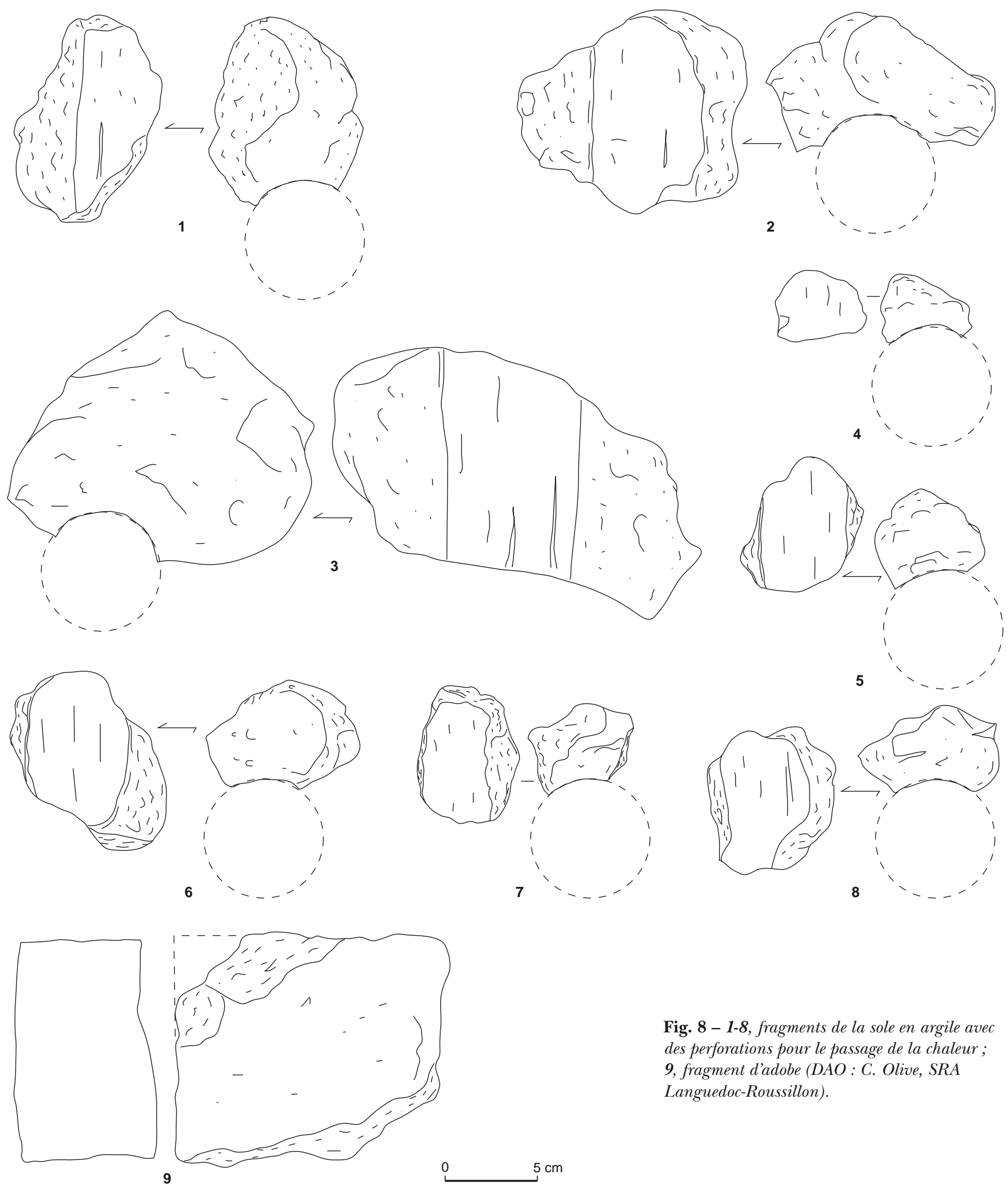

Fig. 8 - 1-8, fragments de la sole en argile avec des perforations pour le passage de la chaleur; 9, fragment d'adobe (DAO : C. Olive, SRA Languedoc-Roussillon). 


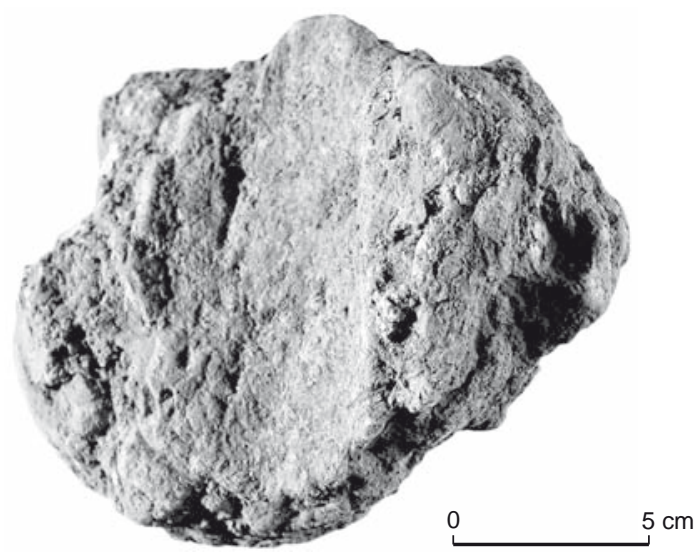

Fig. 9 - Fragment de la sole en argile rubéfiée présentant une perforation (cliché : C. Olive, SRA Languedoc-Roussillon).

\section{LA FOSSE D'ALIMENTATION}

La fosse d'alimentation, située dans le prolongement de l'alandier, était creusée dans le substrat argilo-marneux. Sa forme était elliptique, avec un étranglement en son centre (fig. 10). Longue de 2,75 $\mathrm{m}$ pour une largeur moyenne de 1,65 m, son sol était en légère pente vers l'entrée du four.

Cette zone basse, largement et profondément excavée afin de rendre possible l'alimentation du four ainsi que pour entreposer le bois, se trouvait nettement plus bas que le niveau de circulation environnant et de la sole. Elle était délimitée et encadrée symétriquement par des poteaux qui avaient conservé leur calage de moellons en calcaire. Distants l'un de l'autre de 4,10 m, ils s'organisaient avec un autre trou de poteau situé plus au nord, à $6,10 \mathrm{~m}$, au niveau de la chambre de chauffe (fig. 10 et 11).

Ces poteaux indiquent l'existence d'un bâti en matériaux légers destiné à retenir les terres au bord de l'excavation ou à assurer une protection contre les intempéries.

\section{LA COUVERTURE}

Le four ayant été détruit sous le niveau de la sole, les structures aériennes du laboratoire n'ont pas laissé de traces. Des fragments de torchis, avec empreintes de branchages retrouvés dans le comblement, peuvent laisser supposer la présence d'une coupole réalisée dans ces matériaux, qui devait être reconstruite lors de chaque cuisson.

Toutefois, en regard de la taille des vases à cuire et donc de celle que devait avoir le laboratoire, cette couverture pouvait être fixe. Dans ce cas, comme pour les fours sub-
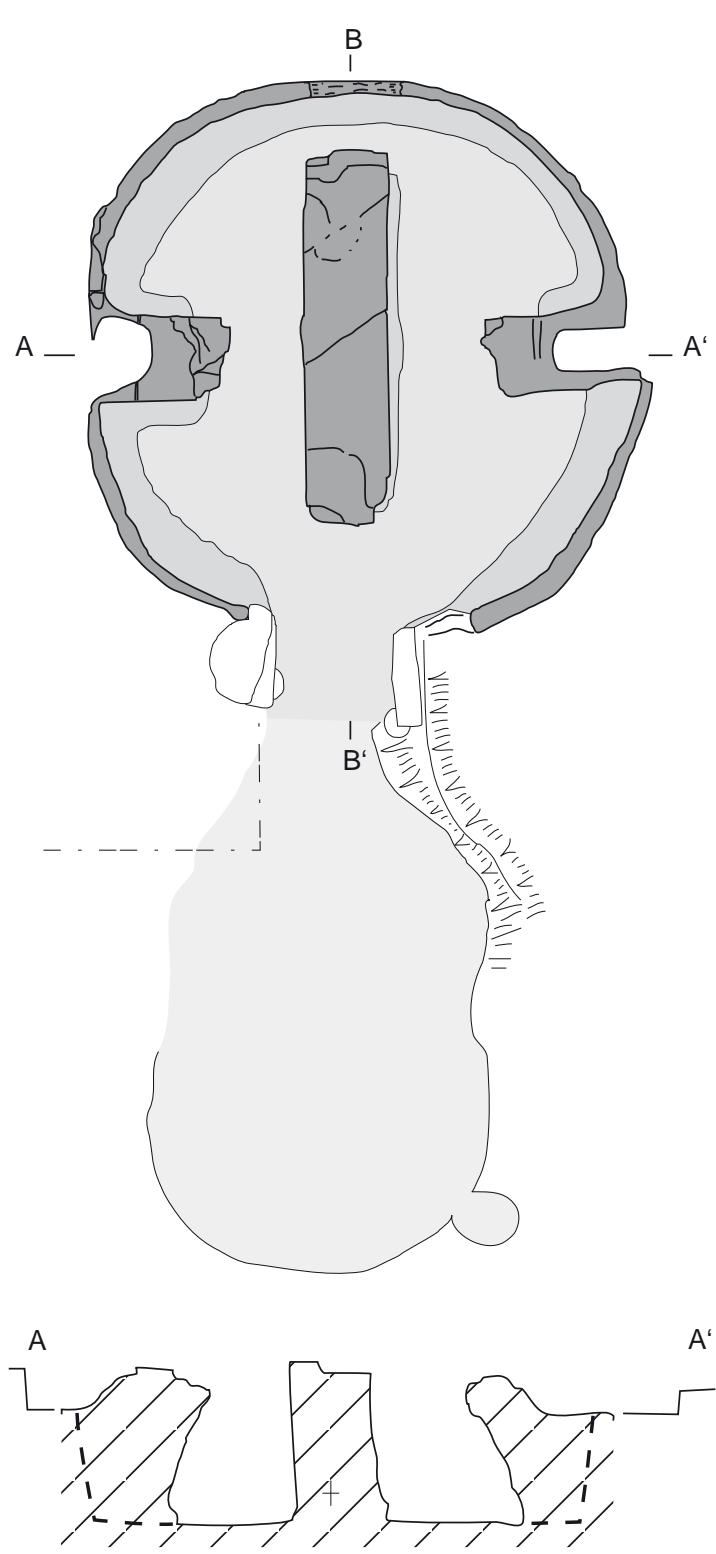

B $B^{\prime}$

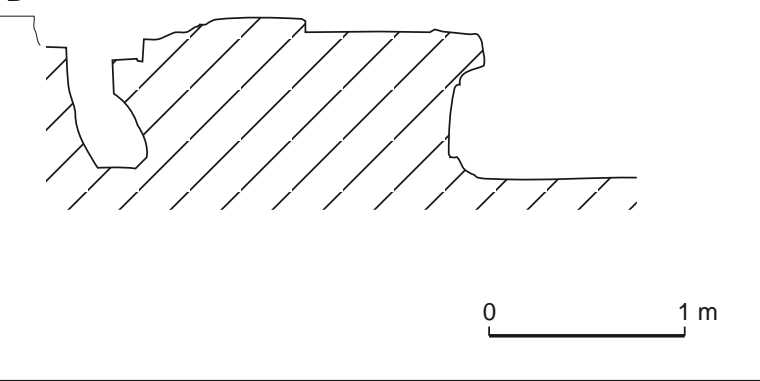

Fig. 10 - Plan et coupes des vestiges du four de potier et de sa fosse d'alimentation (relevés et dessins : C. Olive et D. Ugolini). 


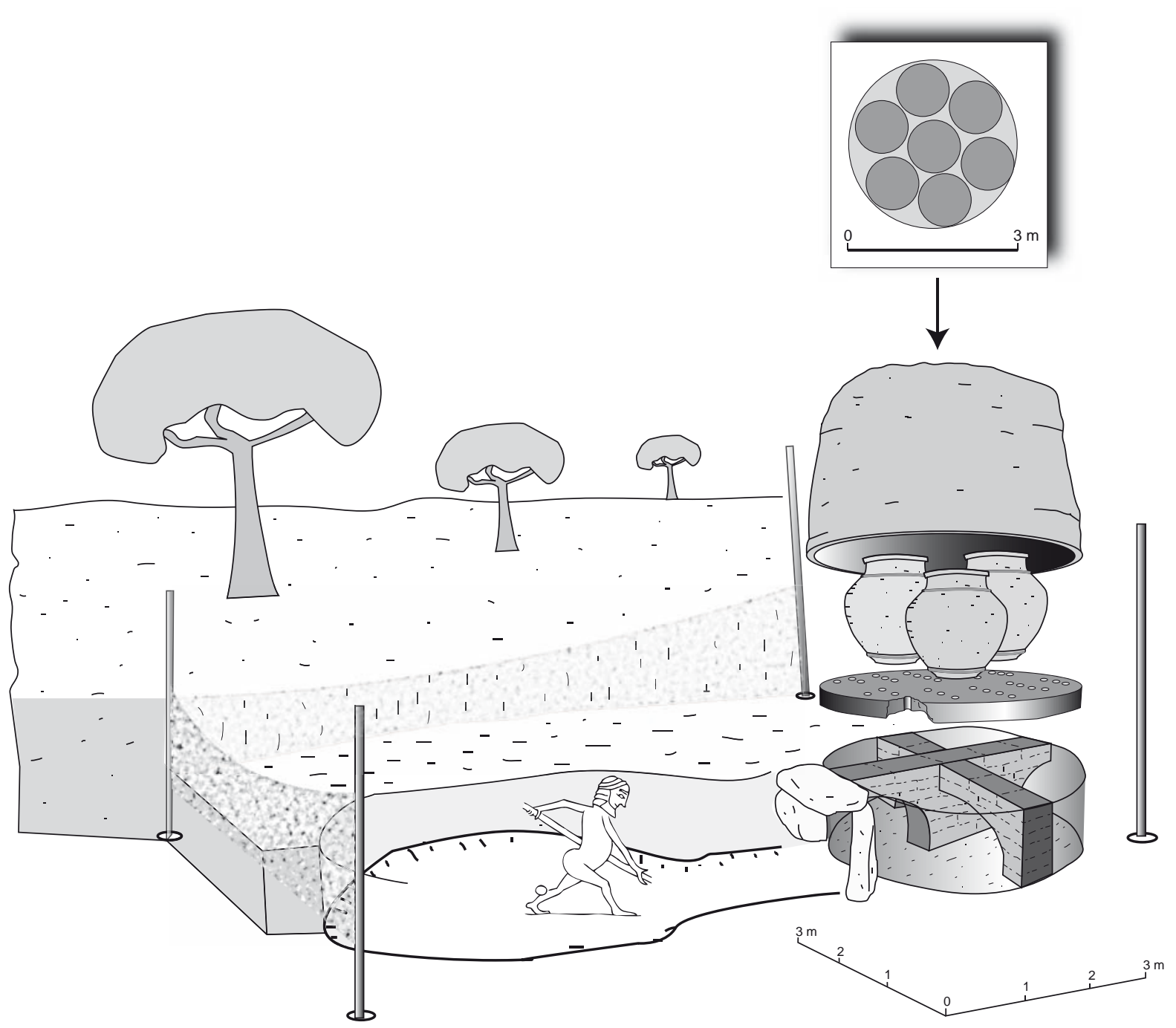

Fig. 11 - Proposition de restitution du four en fonctionnement. La fournée pouvait compter jusqu'à sept pithoi de taille moyenne ( 1 m de diamètre à l'épaulement) disposés sur un seul niveau (DAO : C. Olive, SRA Languedoc-Roussillon).

actuels crétois, les parois de l'espace de cuisson pouvaient être réalisées en adobes, dont de nombreux fragments ont été recueillis ça et là et notamment dans les niveaux bouleversés par les labours (fig. 8 et 9). Les fragments de torchis retrouvés appartiendraient alors au toit d'un laboratoire circulaire, sans doute assez haut.

\section{LE COMBLEMENT}

Le décapage pratiqué à la pelle mécanique a mis au jour les vestiges apparents conservés à la base des labours. Ce nettoyage (us 1102) a permis d'identifier la situation des principaux vestiges, dont le four FR 1009. Lors de la fouille, les différentes parties de la construction ont été repérées : la chambre de chauffe, l'alandier, la fosse d'alimentation et les trous de poteau. Une couche de marne argileuse contenant des cendres, de couleur gris clair, recouvrait l'ensemble des structures (us 1112).

La chambre de chauffe était comblée par une puissante couche de terre marno-argileuse de couleur gris-beige (us 1105) contenant de nombreux fragments d'argile cuite provenant de la construction du four et des fragments de la sole. Des fragments de céramiques ont été également retrouvés : ils appartiennent à des vases à pâte claire, en céramique de cuisine tournée et à des pithoi.

En dessous, une couche de terre de même nature, mais contenant beaucoup plus de cendres, (us 1124) tapissait le fond. Elle contenait de très nombreux fragments d'argile 

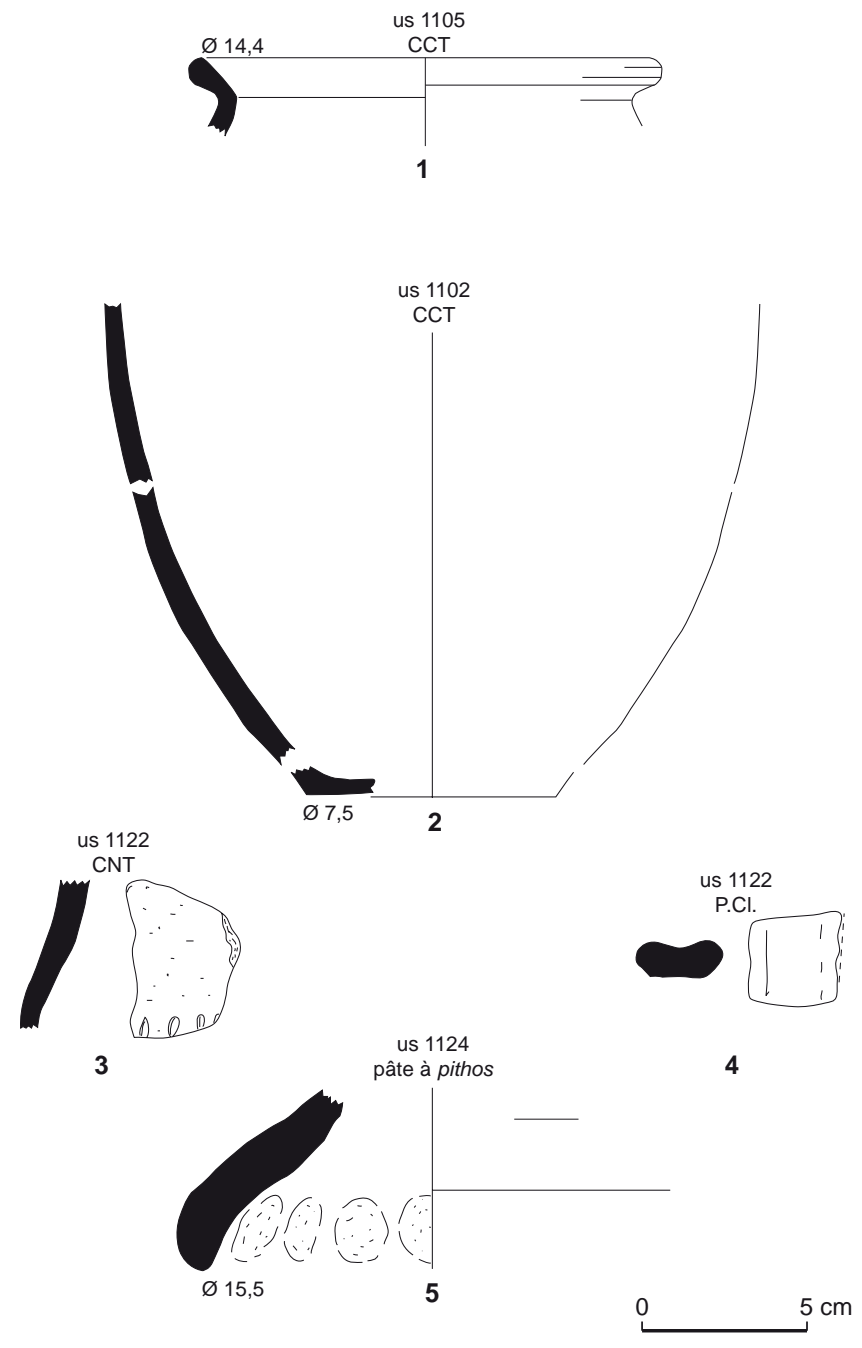

Fig. 12 - Céramiques retrouvées dans le comblement de la chambre de chauffe : 1, 2, céramique de cuisine tournée biterroise; 3, céramique non tournée; 4 , anse de cruche en pâte claire; 5 , pied de vase, ou coupelle ou pièce technique? en pâte à pithos finie au tour lent (DAO : C. Olive, SRA Languedoc-Roussillon).

provenant du bâti du four : fragments d'adobes, éléments de sole (dont certains perforés), fragments de torchis avec empreintes de branchages. Quelques fragments de céramique tournée à pâte claire beige, de céramique de cuisine tournée à gros dégraissant et de pithoi complétaient ce dernier niveau de comblement (fig. 12 à 14 et tabl. I).

Sous le décapage mécanique (us 1102) et la fine couche us 1112, le conduit de l'alandier était comblé par une couche (us 1104) de même nature que celle observée dans la chambre de chauffe (us 1105). Outre des fragments de la construction du four, il comprenait de nombreux moellons en calcaire.
La couche immédiatement en dessous (us 1106) correspond à un décapage de principe. La texture est la même que celle qui la recouvre. On y retrouve des débris de sole et de nombreux fragments de pithoi, des nodules d'argile rubéfiés et des morceaux de chamotte.

En dessous, une fine couche de cendres, très charbonneuse, tranchait nettement (us 1125). Elle contenait des éléments de sole et des fragments de pithoi.

Enfin, le fond de l'alandier (us 1126) était tapissé de charbons de bois et de cendres (tabl. I).

Dans la fosse d'alimentation, sous le décapage us 1102, on a retrouvé une couche marno-argileuse de couleur grise (us 1115), équivalente au comblement voisin (us 1112), qui recouvrait l'ensemble de la fosse.

L'us 1115 se superposait, au débouché de l'alandier, à une petite dépression, comblée par un terrain marno-argileux très cendreux (us 1116), recouvrant à son tour une couche charbonneuse (us 1122) qui tapissait le fond de la dépression. On y a retrouvé des fragments d'adobes, des nodules érodés d'argile cuite, des fragments de céramique à pâte claire, un fragment de céramique modelée, des fragments d'amphores massaliètes et de nombreux fragments de pithoi (tabl. I).

Les éléments en creux, trous de poteau et fosses, étaient recouverts par la fine couche (us 1112) présente sous le décapage général.

À l'extérieur de la fosse d'alimentation, des trous de poteau étaient disposés de part et d'autre, de manière symétrique, et ont été identifiés par la concentration des blocs calcaires servant de calage (fig. 4, TP 1127 et TP 1128). Aucun mobilier n'y a été retrouvé.

$\mathrm{Au}$ nord-ouest du four, on a relevé la présence de deux fosses : FS 1129, comblée de moellons de calcaire et ne contenant aucun mobilier ; FS 1113, uniquement comblée de fragments de pithoi et de quelques débris de sole (tabl. I).

La destruction et le comblement du four ont visiblement été réalisés très rapidement. On y trouve des fragments d'éléments constitutifs de sa structure (fragments de sole, de couverture) et des tessons mélangés au remblai. Tous ces éléments s'étagent à partir du fond jusqu'au niveau d'apparition des vestiges, sans décalage chronologique. Le tout recouvre les restes du foyer ayant servi à cuire la dernière fournée (charbons, cendres). La présence de fragments de la sole dans toutes les couches du comblement confirme un remblaiement très rapide et homogène. Aucune perturbation postérieure n'est venue bouleverser cette structure. 
Tabl. I - Mobilier découvert dans les unités stratigraphiques fouillées : CCT, céramique de cuisine tournée à gros dégraissant biterroise ; CNT, céramique non tournée ; A, amphore ; $P C l$, céramique à pâte claire.

\begin{tabular}{|c|c|c|c|}
\hline US & Classe & Nombre fr./Él. forme & Observation \\
\hline \multicolumn{4}{|l|}{ Décapage } \\
\hline \multirow{5}{*}{ us 1102} & pithos & 1 bord, 11 panses & bord en bandeau \\
\hline & CCT & 1 fond, 9 panses & fond plat \\
\hline & argile cuite & 2 fragments & \\
\hline & CNT préhistorique & 1 panse & \\
\hline & silex & 3 fragments de lames & \\
\hline \multicolumn{4}{|c|}{ Chambre de chauffe } \\
\hline \multirow{7}{*}{ us 1105} & pithos & 1 fond, 22 panses & plat \\
\hline & CCT & 1 bord, 6 panses & bord en amande \\
\hline & $\mathrm{PCl}$ & 8 panses & \\
\hline & A. indéterminé & 1 panse & \\
\hline & adobe & 1 fragment & \\
\hline & sole & 50 fragments & \\
\hline & faune & 1 os brûlé & \\
\hline \multirow{7}{*}{ us 1124} & & 1 bord & en bandeau \\
\hline & pithos & 19 panses & $\begin{array}{l}1 \text { fragment surcuit, } \\
1 \text { fragment craquelé }\end{array}$ \\
\hline & CCT & 1 panse & \\
\hline & \begin{tabular}{|ll} 
vase $\quad$ pièce \\
technique?
\end{tabular} & 2 bords du même vase & en pâte à pithos \\
\hline & sole & 150 fragments & \\
\hline & adobe & 2 fragments & \\
\hline & CNT préhistorique & 3 panses & \\
\hline \multicolumn{4}{|l|}{ Alandier } \\
\hline us 1104 & sole & 7 fragments & \\
\hline \multirow{2}{*}{ us 1106} & pithos & 4 panses & \\
\hline & sole & 10 fragments & \\
\hline $\begin{array}{|lll|}\text { us } & 1125 & \text { et } \\
1126 & & \\
\end{array}$ & pithos & 3 panses & \\
\hline \multicolumn{4}{|c|}{ Fosse d'alimentation } \\
\hline \multirow{6}{*}{ us 1122} & pithos & 1 bord, 26 panses & 8 fragments surcuits \\
\hline & $\mathrm{PCl}$ & 1 anse bifide, 2 panses & $\begin{array}{l}2 \text { panses peinture } \\
\text { rouge }\end{array}$ \\
\hline & CNT & 1 panse & pâte à pithos \\
\hline & A. massaliète & 2 panses & surcuites \\
\hline & adobe & 5 fragments & \\
\hline & argile cuite & 150 fragments & nodules \\
\hline \multicolumn{4}{|l|}{ Fosse } \\
\hline us 1113 & pithos & 50 fragments & surcuits \\
\hline
\end{tabular}

\section{LE FONCTIONNEMENT DU FOUR}

Les éléments conservés de la structure du four (fig. 10), ainsi que la courbure des voûtes, montrent que le four a été arasé sous la sole. Aucun fragment de son élévation ou de sa coupole n'a été identifié avec certitude parmi les débris comblant la chambre de chauffe, l'alandier ou la fosse d'alimentation, même si des fragments de torchis et d'adobes ont été recueillis dans les niveaux bouleversés par les labours.

La sole reposait sur le long mur central et sur les deux piliers latéraux, dont les extrémités formaient des voûtes à encorbellement. Le tout constituait une structure très solide en forme de croix qui supportait le grand poids de la sole, ainsi que celui du chargement des vases à cuire, sans doute encore plus important (fig. 11).

Au niveau de la chambre de chauffe, les espaces voûtés laissaient un espace suffisant pour la libre circulation de la chaleur de part et d'autre des fausses voûtes.

Lalandier formait un couloir d'un peu plus de $50 \mathrm{~cm}$ de longueur dont le revêtement des parois, en blocs calcaires, a été retrouvé. Un doute subsiste sur la nature du linteau.

La fosse d'alimentation présentait une légère pente vers l'entrée du four, ce qui facilitait l'introduction des braises dans la chambre de chauffe.

Les trous de poteau et la structure de protection à laquelle ils appartenaient délimitaient la zone excavée pour les besoins de l'aménagement de la fosse d'alimentation, qui se trouvait en contrebas par rapport au niveau du sol environnant (fig. 11).

On peut restituer la profondeur de la chambre de chauffe lorsqu'elle était en état de marche à plus ou moins $1,05 \mathrm{~m}$, c'est-à-dire le creusement qu'il a fallu réaliser du sol de la chambre de chauffe au sommet de la sole. L'espace entre la base de la sole et le fond de la fosse mesurait donc à l'origine $0,88 \mathrm{~m}$. Le diamètre du four au niveau du sol approchait 2,70-2,80 m.

Aucune donnée sûre ne permet la restitution du laboratoire. Toutefois, les traces de rubéfaction visibles sur le pourtour du four laissent penser que celui-ci possédait une paroi épaisse d'au moins $0,10 \mathrm{~m}$ et que sa base, comme cela est souvent le cas, se trouvait à un niveau inférieur ou égal au sol environnant, pour faciliter l'enfournement et le défournement de la production.

Les matières premières nécessaires au fonctionnement de l'atelier ont pu être prélevées sur place. Le ruisseau de Mazeran fournissait de l'eau en abondance puisqu'il fait partie d'un riche réseau hydrique se développant sur le versant occidental des collines de Saint-Jean-de-Libron, derrière lesquelles coule le Libron. L'argile pouvait être prélevée tout autour de l'atelier, dans des strates facilement accessibles à partir de la surface, au pied de ces mêmes vallonnements. Le quartzite et le sable utilisés comme dégraissant pouvaient aisément être récupérés dans les lits de l'Orb ou du Libron, qui charrient une grande quantité de ces matériaux depuis les avant-monts des hauts cantons 
de l'Hérault. Le mica blond ou argenté, si caractéristique des productions biterroises, provient lui aussi des hauts cantons de l'Hérault (monts de l'Espinouse, Caroux, etc.), où il est particulièrement abondant. Il a pu également se retrouver naturellement dans les argiles prélevées pour le façonnage des céramiques. Le bois, dont il fallait de grandes quantités pour assurer la cuisson dans un four d'une telle dimension, pouvait être prélevé à proximité, immédiatement au nord-est. Les nombreuses prospections réalisées dans ce secteur révèlent en effet un vide dans l'occupation du sol, pour toutes les époques, sans doute dû à la présence d'une forêt (Mazière et al., 2001 ; Ugolini, Olive, 2009).

On peut encore rappeler que la vallée du Libron est particulièrement favorable à l'installation des potiers, dont les ateliers ont été retrouvés en grand nombre pour les époques romaine (Haut-Empire et Bas-Empire) et médiévale ${ }^{9}$, sans doute en raison de la proximité conjuguée des matières premières et d'une importante agglomération consommatrice de céramiques.

Enfin, l'atelier est situé en bordure d'un axe de communication reliant Béziers au site de la Monédière, à Bessan. Quelques indices archéologiques marquent l'existence de cette voie, même s'il n'a pas été possible d'en retrouver matériellement les surfaces de circulation à proximité immédiate du four. Ainsi, une fosse contenant des fragments d'amphores massaliètes a été retrouvée à environ $1,5 \mathrm{~km}$ à l'ouest de l'atelier, au carrefour des Maréchaux (Olive, 1995) et, non loin du four, sous les niveaux de circulation de la voie Domitienne, des couches de la fin du VI ${ }^{\mathrm{e}}$ s. et $d u \mathrm{~V}^{\mathrm{e}} \mathrm{s}$. av. J.-C. pourraient appartenir à une chaussée (Jandot, Gomez et al., 2003). Ces observations ont été confirmées lors d'une opération postérieure (Gomez et al., 2004). Une telle voie a certainement favorisé le choix d'implantation de l'atelier de potier et, quoi qu'il en soit, la présence d'un chemin était nécessaire pour l'approvisionnement en matières premières pour la fabrication et la cuisson des pithoi, comme pour le transport des produits finis.

\section{LE MOBILIER}

La céramique retrouvée dans les couches de comblement du four appartient principalement aux productions

9. Pour l'époque romaine, autour de Béziers, les productions sont les suivantes : amphores, céramiques à pâte claire, brune orangée biterroise, imitations de céramiques africaines de cuisine, matériaux de construction, dont des tuiles (sur les communes de Béziers, Boujansur-Libron, Corneilhan, etc.) et, pour le Moyen Âge, «pégaus » et matériaux de construction (sur les communes de Béziers et Boujansur-Libron). biterroises (Ugolini, Olive, 1987-1988 ; Ugolini et al., 1991 ; Ugolini, 2002 et 2003 ; Ugolini, Olive, 2006). Bien que leur nombre soit limité, les fragments sont bien caractéristiques (fig. 12 et tabl. I).

- La céramique à pâte claire $(\mathrm{PCl})$ est présente dans l'us 1105 , avec 8 panses à pâte très fine de couleur beige légèrement orangé, et dans l'us 1122, avec deux panses similaires dont une couverte d'un enduit de couleur rouge. Le fragment de l'anse bifide d'une cruche complète le lot (fig. 12, no 4). Ces céramiques sont typiques des pâtes claires produites à Béziers.

- Des fragments de céramique de cuisine tournée à gros dégraissant (CCT) ont été retrouvés dans plusieurs strates. De l'us 1102 provient un fragment de fond plat de marmite, à pâte grise assez mal cuite et dégraissant de quartzite, et neuf fragments de panse de même composition (fig. 12, $n^{\circ} 2$ ). L'us 1105 a livré un fragment de bord en amande, très caractéristique, fait d'une pâte très sombre, bien cuite, contenant un dégraissant de petits fragments de quartzite et de petits graviers, et dont l'épiderme brun-noir, très soigné, présente des particules de mica blond (fig. 12, $\mathrm{n}^{\mathrm{O}} 1$ ), ainsi que six autres fragments de panses de même composition. De l'us 1124 provient un fragment de panse présentant la même composition de pâte.

Ces fragments sont tout à fait conformes aux standards biterrois. L'unique forme mise au jour ici, la marmite à fond plat et à bord en amande (sur laquelle s'adaptait un couvercle), est la forme principale de cette classe céramique massivement produite par les ateliers biterrois en plusieurs tailles, entre le $\mathrm{VI}^{\mathrm{e}}$ s. et la fin du $\mathrm{IV}^{\mathrm{e}}$ s. av. J.-C., et utilisée à Béziers de manière exclusive pour les préparations culinaires ${ }^{10}$.

- Les fragments de vases non tournés (CNT) sont principalement préhistoriques. Issus d'une fosse recoupée lors du creusement de la chambre de chauffe (fig. 6), ils sont antérieurs à notre contexte. Un seul fragment d'épaulement de vase modelé est contemporain du four. Retrouvé dans l'us 1122, son épiderme est beige à l'extérieur alors que sa surface interne est noire et il est décoré d'une bande d'impressions (fig. 12, $\mathrm{n}^{\circ} 3$ ).

10. Cas unique en Gaule, Béziers a développé massivement une production de vaisselle tournée à feu (Ugolini, Olive, 1987-1988), dont la forme principale imite l'olla étrusco-italique. Cet aspect du faciès mobilier local a été soulevé il y a déjà quelques années (Ugolini et al., 1991, p. 167-171) et a été repris, depuis, sous différents angles, y compris dans le cadre de la comparaison avec les autres sites (Ugolini, Pezin, 1993 ; Olive, Ugolini, 1997 ; Ugolini, 2000, 2002 et 2003 ; Ugolini, Olive, 2006 ; Ugolini, Olive dir., 2006). 


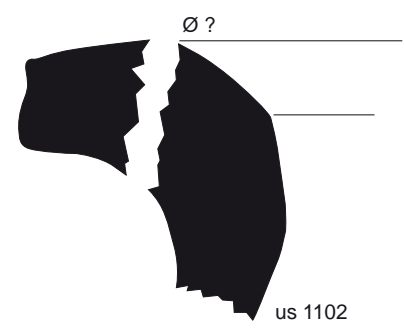

1

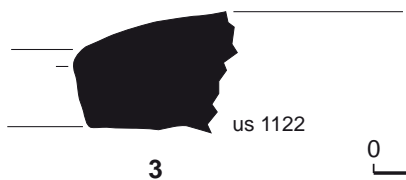

0

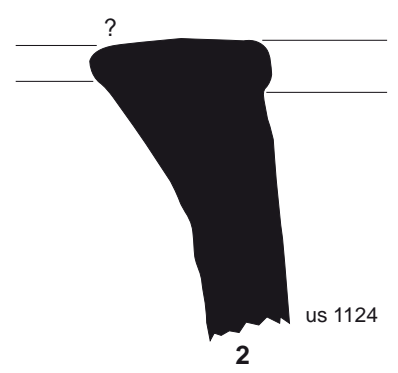

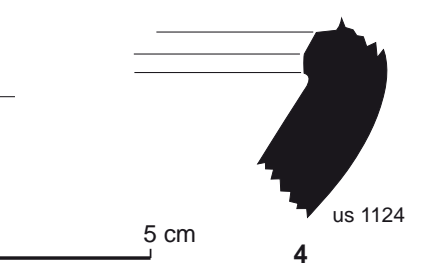

$5 \mathrm{~cm}$

4
Fig. 13 - Fragments de pithoi issus du comblement du four (DAO : C. Olive, SRA Languedoc-Roussillon).

- Les fragments d'amphores sont peu nombreux : dans l'us 1105, un fragment indéterminé de panse pourrait appartenir à une amphore grecque ou ibérique ; dans l'us 1122, deux fragments d'amphores massaliètes sont surcuits (traces d'éclatement provoqué par la chaleur). Aucun bord n'a été retrouvé.

- Les fragments de pithoi sont les plus nombreux : plus de 140 fragments ont été mis au jour pendant la fouille. De l'us 1105 proviennent 23 gros fragments à pâte soit beige, soit orangée, à dégraissant de quartzite. De l'us 1124 proviennent un bord triangulaire à la surface externe peignée, présentant une pâte orangée avec un dégraissant de quartzite (fig. 13, $\mathrm{n}^{\mathrm{o}} 2$ ) ; un fragment d'épaulement avec un bandeau, dont la pâte est analogue (fig. 13, no 4) ; neuf fragments à surfaces peignées et trois fragments dont la surface est très érodée et dont la pâte est de couleur mauve, caractéristique de surcuits ; et, enfin, cinq fragments présentant une pâte craquelée par surcuisson ou par effet d'un refroidissement trop rapide (fig. 14). D'autres fragments ont été retrouvés dans l'us 1106 (quatre panses). Des us 1125/1126 proviennent deux fragments d'un bord en bandeau non dessinable et un fragment de panse. De l'us 1122, un bord (fig. 13, no 3), treize panses, cinq fragments érodés et huit fragments à la teinte orange vif trahissant une surcuisson. Enfin, dans la fosse 1113, les fragments de pithoi présentent une pâte à dégraissant de quartzite, légèrement micacée, cassante, craquelée, de couleur rouge vif, visiblement surcuite (33 fragments), et d'autres, dont la surface intérieure

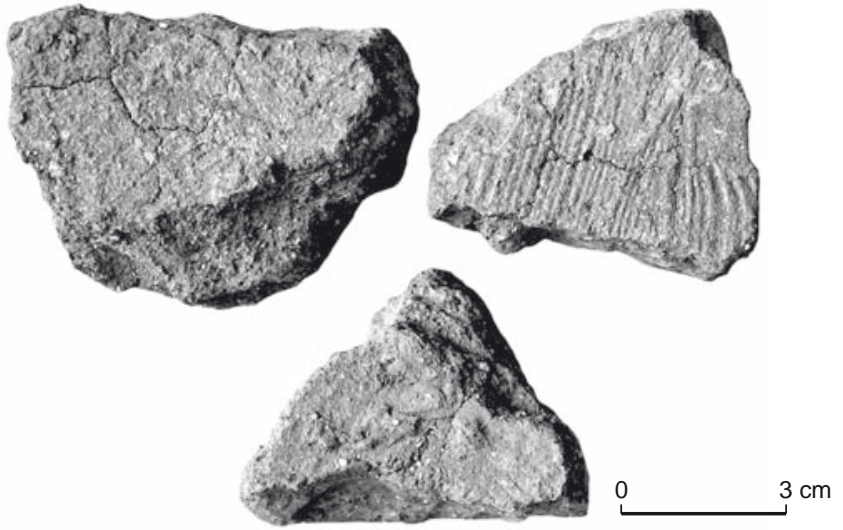

Fig. 14 - Fragments de pithoi craquelés par surcuisson ou par un refroidissement trop rapide (cliché : C. Olive, SRA LanguedocRoussillon).

est peignée, montrent un épiderme extérieur craquelé (17 fragments).

- Le pied d'un vase (à moins que ce ne soit le bord d'une coupelle ou bien une pièce technique ?) (fig. 12, $\mathrm{n}^{\circ} 5$ ), retrouvé dans l'us 1124, a un diamètre relativement petit $(15,5 \mathrm{~cm})$, des parois épaisses faites d'une pâte beige-orange très cuite, contenant de nombreuses particules très fines de mica doré. Le dégraissant est fait de quartzite. Sa pâte paraît légèrement surcuite et sa texture se rapproche de celle des pithoi, des tuiles et d'autres objets produits en Biterrois. La finition de cette pièce est assez fruste : réalisée au tour lent (traces régulières de tournage sur sa face externe, forme régulière), elle a été décorée d'une frise de dépressions sur sa paroi interne, lorsque la pâte était encore fraîche (traces de pressions faites avec les doigts).

\section{DATATION}

Il n'est pas aisé de caler chronologiquement l'abandon du four et c'est l'association des céramiques provenant du comblement, qui s'inscrit dans la chronologie de la ville de Béziers et de ses productions, qui permet quelques remarques.

Les fragments de vases à pâte claire sont chronologiquement peu significatifs. L'anse bifide appartient à une cruche, forme que l'on rencontre couramment à Béziers dès le $\mathrm{VI}^{\mathrm{e}} \mathrm{s}$. av. J.-C.

Les fragments de marmites en céramique de cuisine tournée peuvent également avoir une chronologie longue et les éléments morphologiques relevés ici permettent tout juste de dire que l'on se place après 525 et avant la fin du IV $^{\text {e }}$ s. av. J.-C. 
Les éclats d'amphores massaliètes (à gros dégraissant de mica) peuvent être placés entre 500 et 300 av. J.-C.

Les pithoi se retrouvent, en ville, surtout dans les couches des $\mathrm{V}^{\mathrm{e}}$ s. et $\mathrm{IV}^{\mathrm{e}} \mathrm{s}$. av. J.-C., qui sont les mieux connues, mais aussi dans celles de la seconde moitié du $\mathrm{VI}^{\mathrm{e}}$ s. av. J.-C., moins nombreuses car profondes et rarement atteintes. On peut préciser que les fragments attestés dans les niveaux du $\mathrm{VI}^{\mathrm{e}} \mathrm{s}$. av. J.-C. ont la même pâte que celle qui est observée pour les fragments découverts dans et autour de ce four. Cette pâte est majoritaire, parmi les pithoi des niveaux archéologiques urbains, jusque vers 350 av. J.-C. (Ratsimba, 2002 et 2006, pâte I).

On tiendra compte également du fait que l'on a relevé à proximité, sous les niveaux de circulation de la voie Domitienne, des niveaux probablement contemporains de la période d'utilisation du four. Le mobilier est représenté par des fragments d'amphores étrusques de la seconde moitié du $\mathrm{VI}^{\mathrm{e}} \mathrm{s}$. et des fragments d'amphores massaliètes.

En conséquence, comme la structure a été comblée rapidement après son abandon, les observations réunies ci-dessus invitent à retenir l'hypothèse que le four et l'atelier ont fonctionné entre la fin du $\mathrm{VI}^{\mathrm{e}} \mathrm{s}$. et le milieu du $\mathrm{IV}^{\mathrm{e}} \mathrm{s}$. av. J.-C.

\section{UNE PRODUCTION DE PITHOI}

Deux classes de céramique offrent des fragments surcuits (de couleur mauve ou dont la pâte a changé de texture sous l'effet de la chaleur) ou ayant subi d'autres accidents de cuisson ou de séchage (présentant un épiderme craquelé) : des fragments d'amphores massaliètes et des fragments de pithoi.

C'est à ces derniers qu'appartient le plus grand nombre de fragments retrouvés, qu'ils proviennent du comblement du four, des zones périphériques, ou même du terrain bouleversé par les labours, qui a restitué notamment de nombreux fragments sous-cuits.

Il est difficile de croire que cet atelier a produit des amphores massaliètes en regard du nombre infime de fragments recueillis ainsi que de la taille du four, trop petit pour les habituelles cargaisons d'amphores, comme le montre le four contemporain de Marseille (Rothé, Tréziny, 2005, fig. 519).

La seule alternative possible est alors celle d'une production de pithoi, ce qui tient compte à la fois du nombre de sous-cuits et de surcuits mis au jour, ainsi que de la taille de la structure et de ses caractéristiques techniques, le four étant indiscutablement destiné à la réalisation de pièces grosses et lourdes.

\section{UNE PÂTE GARACTÉRISTIQUE}

Les recherches sur les pithoi de Béziers, dont la production locale est supposée depuis longtemps (Ugolini et al., 1991, p. 185), ont mis en évidence le fait que les pièces issues des contextes archéologiques de la ville datés entre la fin du VI ${ }^{\mathrm{e}} \mathrm{s}$. et le $\mathrm{IV}^{\mathrm{e}}$ s. av. J.-C. ont principalement la " pâte de type I », définie comme suit : «Cette pâte présente le plus souvent des colorations brun rougeâtre, mais certains exemplaires tendent vers le gris ou des teintes plus orangées. La texture est toujours sableuse et plus dense que la moyenne des autres catégories. Le dégraissant est majoritairement constitué de calcite pilée $(\varnothing<1 \mathrm{~mm})$ et de rares graviers de quartz blanc ou rosé ( $\varnothing=2$ à $5 \mathrm{~mm}$ ). D’autres éléments sont présents mais dans de moindres proportions : de petites particules de mica doré et argenté, de petits grains anguleux de couleur noire ou lie-de-vin et parfois des fragments de coquillages et de céramiques pilées. En coupe, on constate que le dégraissant est bien réparti. Il s'agit de la pâte dominante qui correspond aux productions du four fouillé à la périphérie de la ville de Béziers. »(Ratsimba, 2002, p. 16 et 2006).

D'autres ateliers ont dû être actifs en Biterrois ${ }^{11}$ et il se peut que celui de La Domitienne n'ait pas été le seul à produire des pithoi avec cette même pâte. Mais ce sont bien les produits présentant les caractéristiques décrites ci-dessus qui sont majoritaires en ville et qui sont aussi les plus anciens : $86 \%$ des fragments de pithoi mis au jour à Béziers pour la période comprise entre la fin du VI ${ }^{\mathrm{e}} \mathrm{s}$. et la première moitié du $\mathrm{V}^{\mathrm{e}} \mathrm{s}$., et encore entre $50 \%$ et $60 \%$ au IV ${ }^{\mathrm{e}}$ s. (Ratsimba, 2002, p. 17-18).

\section{FAÇONNAGE ET MORPHOLOGIE}

Le mobilier recueilli lors de la fouille de ce four ainsi que les recherches effectuées sur les pièces provenant des niveaux archéologiques de la ville ${ }^{12}$ permettent de proposer une vue d'ensemble de cette production et d'isoler ainsi le " groupe Domitienne ", ce qui est original et constitue une première (fig. 15 à 17).

11. Deux autres types de pâte relevés à Béziers peuvent être également des productions locales (pâtes III et IV). D'autres sont des importations de Provence (pâte II), ou correspondent à des séries connues en Languedoc oriental (pâte V) ou sont d'origine audoise (pâte VI, caractérisée par un abondant dégraissant de coquillages broyés) (Ratsimba, 2002, p. 16-17 et p. 33). Cette dernière classe (pâte VI), attestée tardivement à Béziers (à partir de la seconde moitié du IV ${ }^{\mathrm{e}} \mathrm{s}$.), a ses ateliers localisés dans le Narbonnais depuis longtemps (Héléna, 1937, p. 304).

12. Les observations ont été faites à partir du mobilier archéologique provenant des fouilles de la place de la Madeleine, de la rue Mairan, de la Poste, de la colline Saint-Jacques, des rues du Quatre-Septembre, des Sœurs-Grises et de la République. 
500-450 av. J.-C.
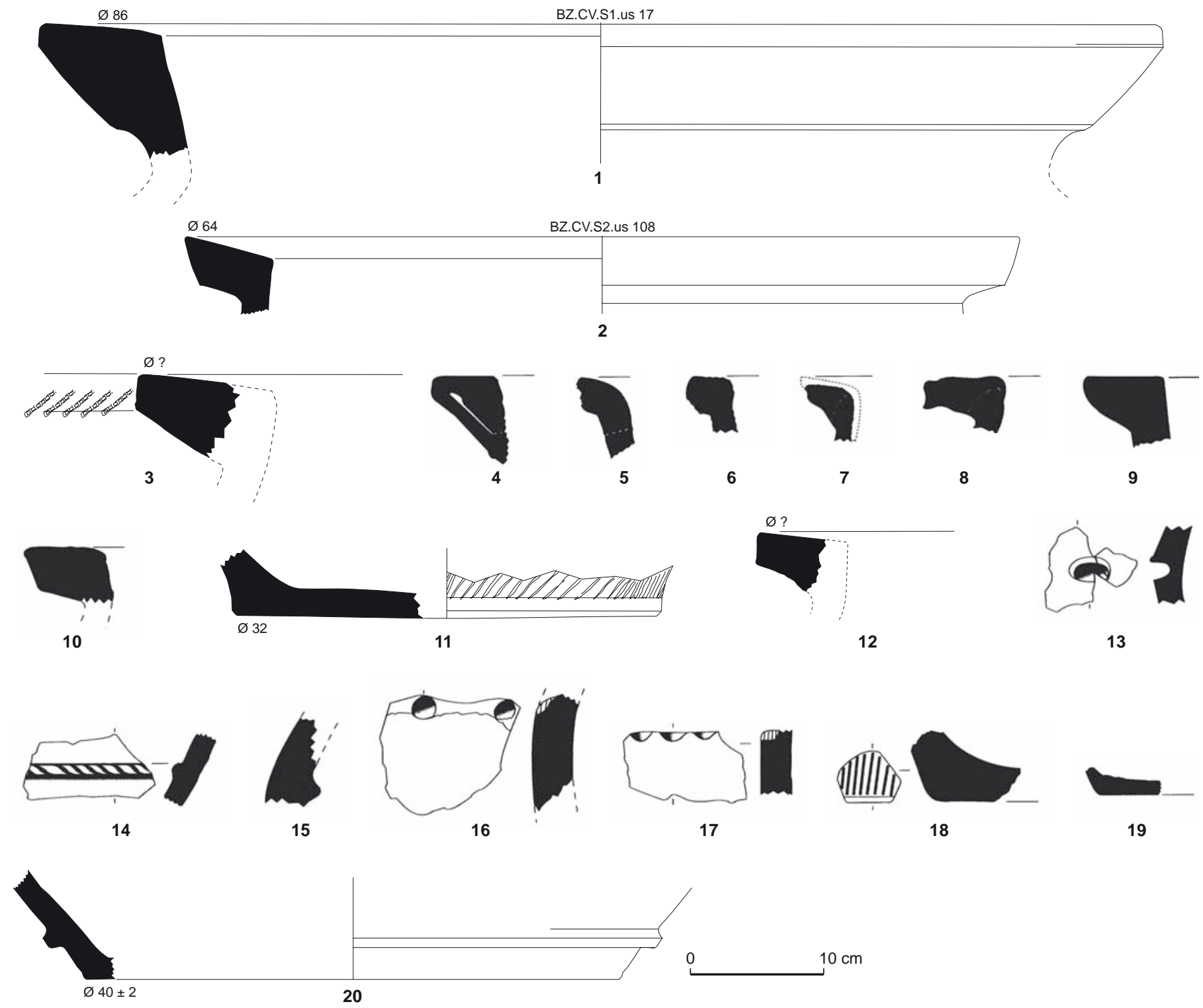

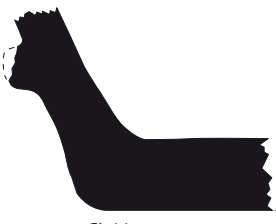

$\varnothing 41$

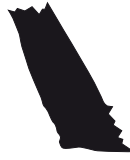

$\varnothing 36$

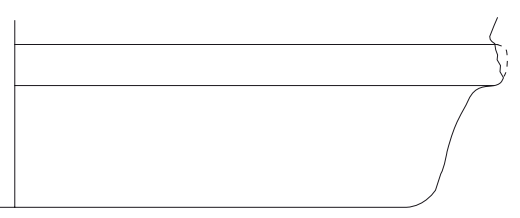

21

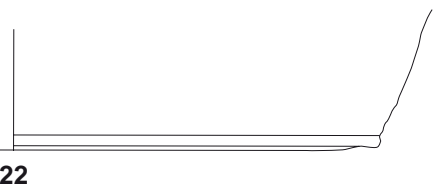

Fig. 15 - Pithoi biterrois en pâte de type I provenant des niveaux archéologiques de Béziers, datés de la première moitié du $V^{e}$ s. av. J.-C. (dessins : A. Ratsimba, Inrap et C. Olive, SRA LanguedocRoussillon). 
450-400 av. J.-C.
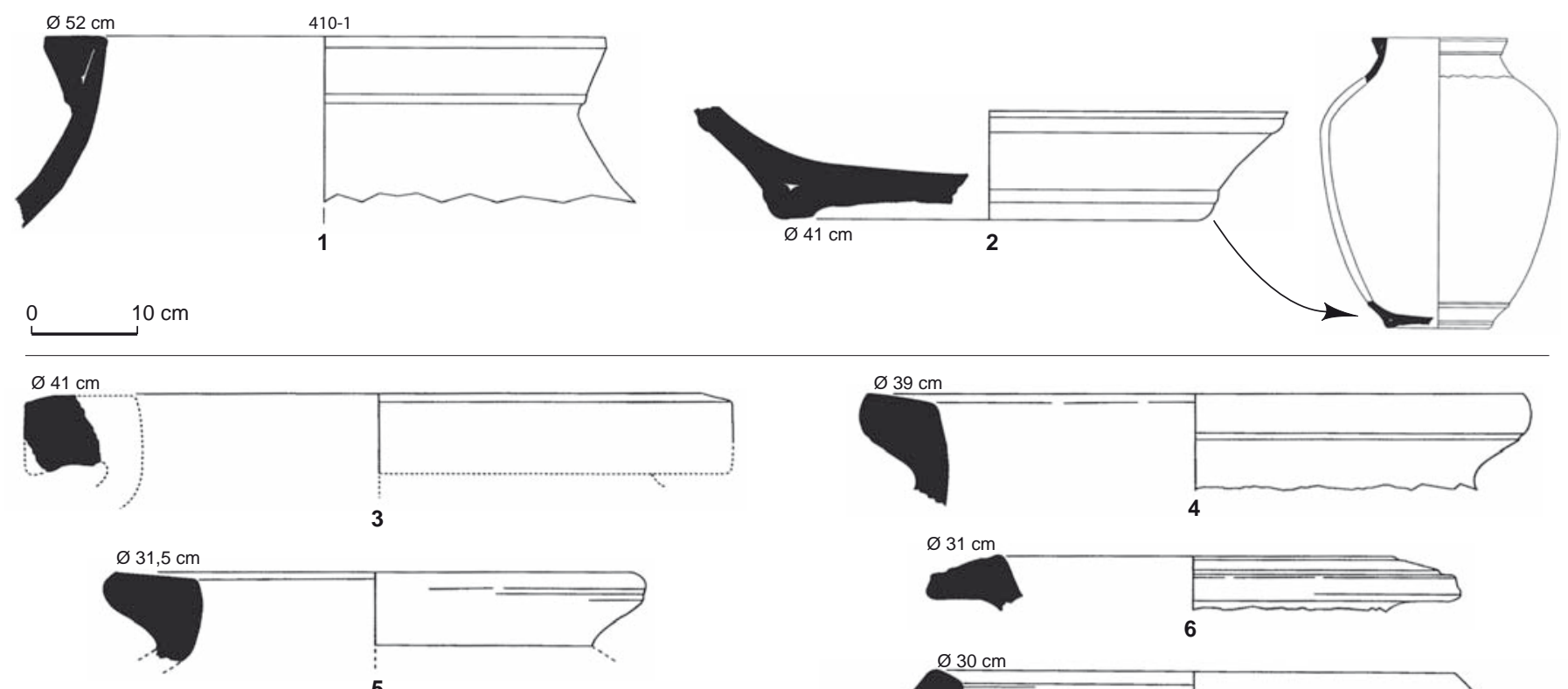

$\varnothing 31 \mathrm{~cm}$
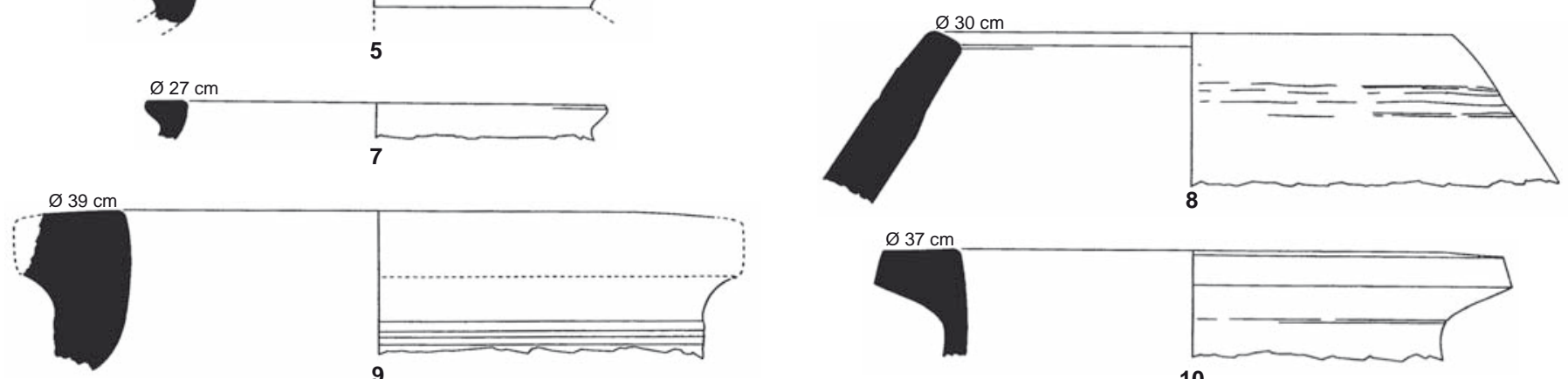

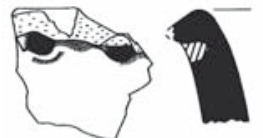

11

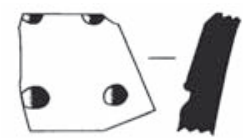

18

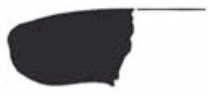

23

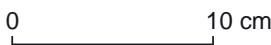

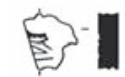

19

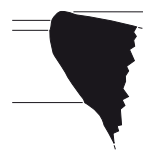

24

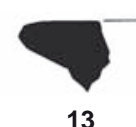

12

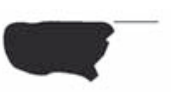

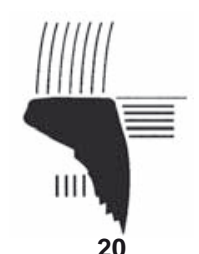

20

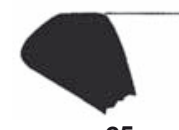

25
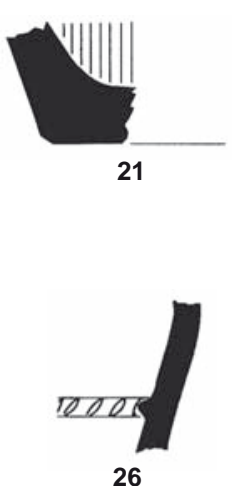

26


15

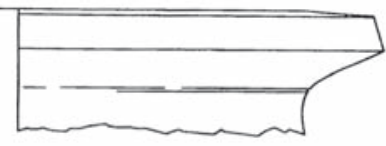

10

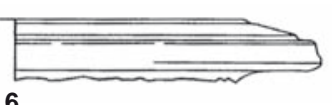

14
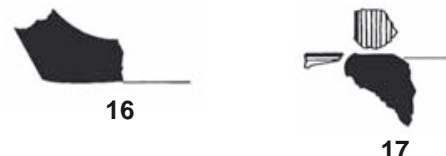

17

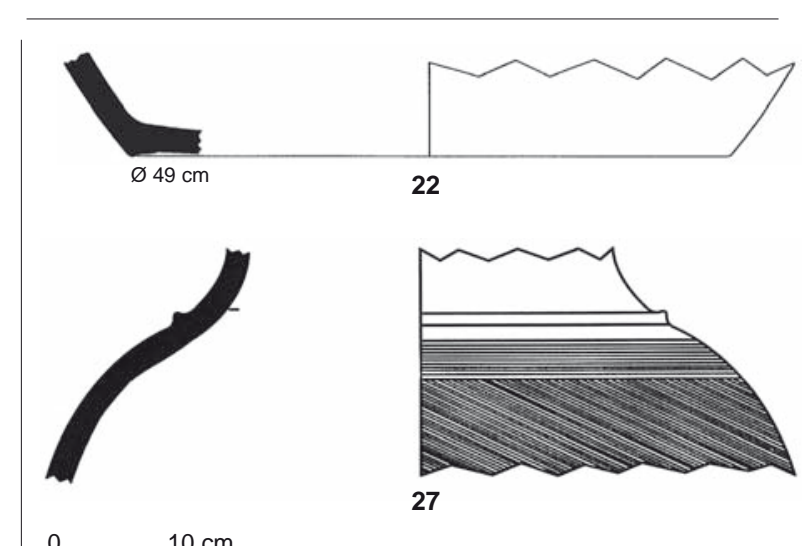

$10 \mathrm{~cm}$

Fig. 16 - Pithoi biterrois en pâte de type I provenant des niveaux archéologiques de Béziers, datés de la seconde moitié du V $V^{e}$ s. av. J.-C. (dessins : A. Ratsimba, Inrap et C. Olive, SRA Languedoc-Roussillon). 
400-350 av. J.-C.
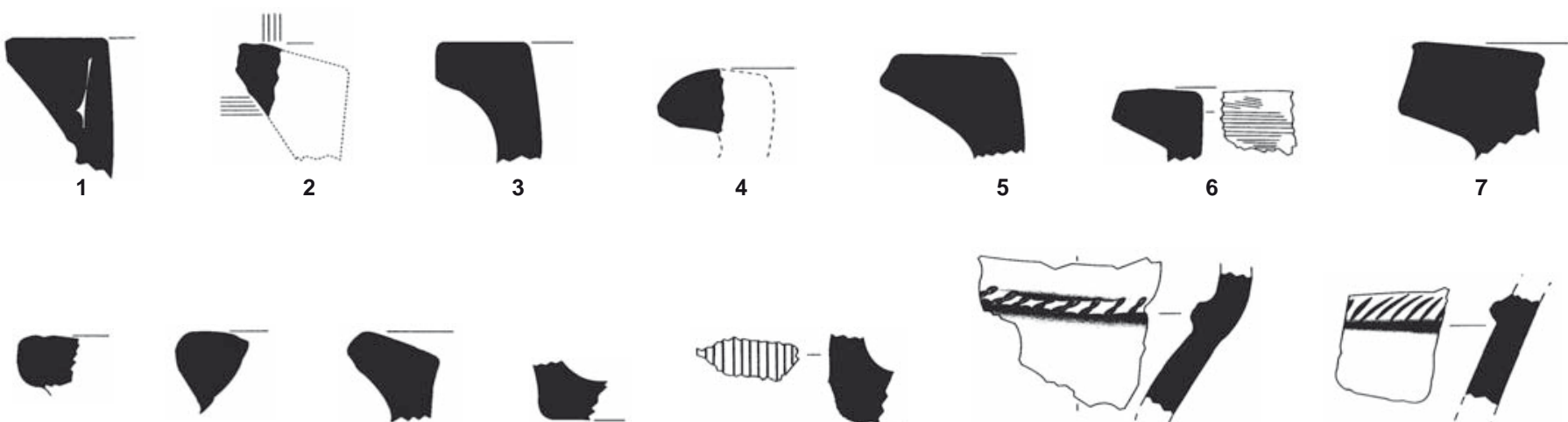

8

9

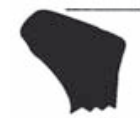

10

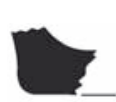

11

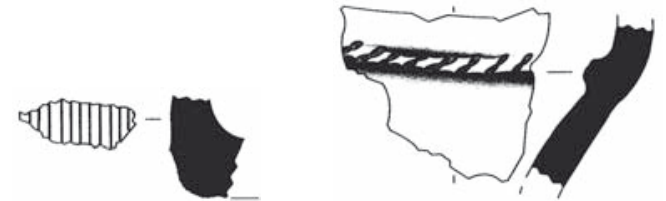

13

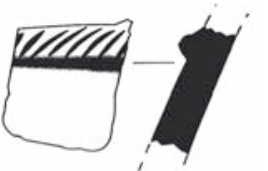

14

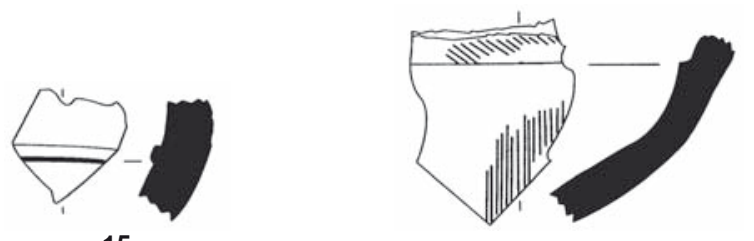

16
12

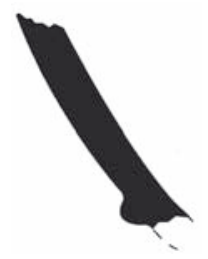

17

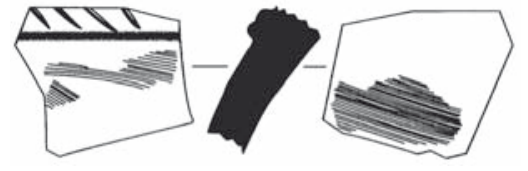

18

350-300 av. J.-C.

$\emptyset 25 \mathrm{~cm}$

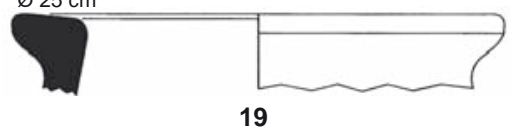

19
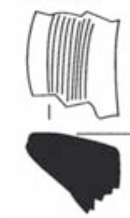

20

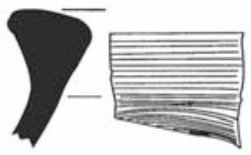

21

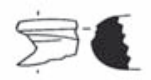

22

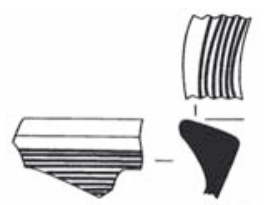

27

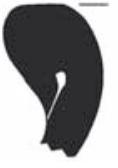

28

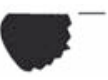

23

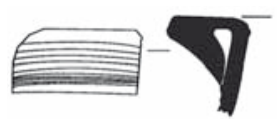

24

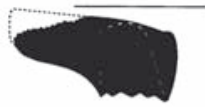

30

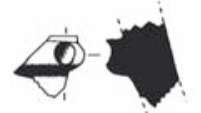

31
㑑伹

32

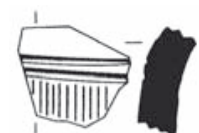

33

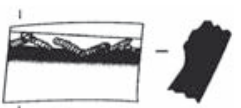

34

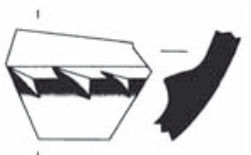

35

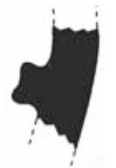

36

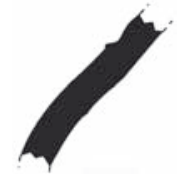

37

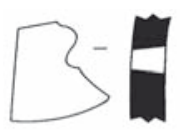

38

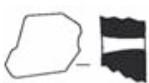

39

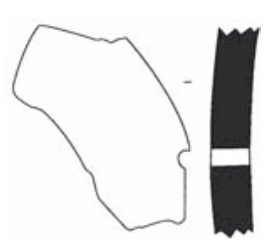

40

$0 \quad 10 \mathrm{~cm}$

Fig. 17 - Pithoi biterrois en pâte de type I provenant des niveaux archéologiques de Béziers :

1-18, première moitié du IV s. av. J.-C. ; 19-40, seconde moitié du IVe s. av. J.-C. (dessins : A. Ratsimba, Inrap). 
Ces pithoi ont été montés avec la technique du colombin étiré. Certaines parties ont fait l'objet d'un tournage, se traduisant par des stries du tour très nettes (Ugolini et al., 1991, p. 183). Il s'agit des bords $(54,5 \%)$ et des fonds $(29,5 \%)$, alors que ce traitement est rare pour les panses $(7 \%)$ et ne doit concerner que des pièces relativement petites. En d'autres termes, le pithos était assemblé à partir de plusieurs éléments préparés séparément.

La variabilité morphologique est grande. La forme du bord, la taille, le décor font que chaque pièce est unique.

Toutefois, les bords à profil triangulaire, à lèvre aplatie (par ex. fig. 15) ou arrondie (par ex. fig. 16), représentent $75 \%$ du total, ce qui montre une nette préférence pour cette forme.

Quelques bords présentent un décor peigné (par ex. fig. 16, no 20 et fig. 17, $n^{\text {os }} 24$ et 27) à partir de la seconde moitié du $\mathrm{V}^{\mathrm{e}} \mathrm{s}$. av. J.-C. et, pendant tout ce siècle, des cordons digités ou avec des impressions réalisées à la molette peuvent être placés au niveau de la lèvre (par ex. fig. $15, \mathrm{n}^{\circ} 3$ et fig. $16, \mathrm{n}^{\mathrm{o}} 11$ ).

Les diamètres mesurés à l'extérieur du bord s'échelonnent entre $25 \mathrm{~cm}$ et $86 \mathrm{~cm}$. La majorité est supérieure à $35 \mathrm{~cm}$. En d'autres termes, ces pithoi sont souvent grands.

Les fragments de panses portent fréquemment un peignage $(40 \%)$, soit sur les deux faces $(20 \%)$, soit sur l'une des deux (10\% pour chacune des deux possibilités). À l'intérieur, le peignage est proche de l'horizontale, peut-être pour faciliter l'adhérence de la résine. À l'extérieur, ce traitement, souvent plus oblique, avait un but décoratif, mais il devait aussi rendre le vase moins lisse et donc moins glissant lors des manipulations (fig. 16, $\left.\mathrm{n}^{\mathrm{o}} 27\right)$.

Outre le peignage, le décor le plus fréquent est l'application à la base du col ou de la panse de cordons en relief, portant parfois des incisions obliques qui, dans un cas, sont réalisées à la molette (fig. 17, no 34).

Certains pithoi de cette production portent une couverte blanchâtre sur les deux faces (7\% des fragments). Cette particularité a également été observée sur des pièces plus récentes ( $\mathrm{III}^{\mathrm{e}}-\mathrm{I}^{\mathrm{er}} \mathrm{s}$. av. J.-C.) trouvées sur d'autres sites de la région. Elle a été considérée comme un décor de couleur blanchâtre ou jaunâtre peint sur le haut du vase et coulant « en bandes » sur sa partie inférieure (Tardieu, 1976, p. 77). Il est intéressant de relever que les potiers crétois faisaient tremper les vases quelques jours, après cuisson et complet refroidissement, dans des grandes cuves remplies d'eau additionnée de chaux. Ce traitement était destiné à les rendre moins poreux (Gouin, Vogt, 2002). Il est

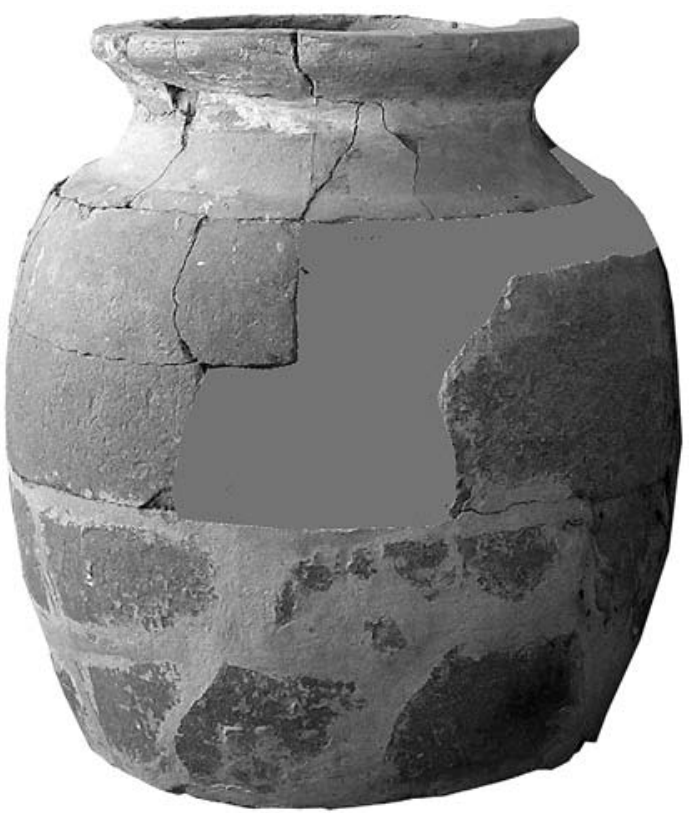

Fig. 18 - Pithos biterrois en pâte de type I presque entier mis au jour à Ensérune (Nissan-lez-Ensérune, Hérault). Hauteur estimée de la pièce complète : $\pm 1,30$ m (cliché : C. Olive, SRA LanguedocRoussillon).

donc possible que les pithoi biterrois aient reçu la même finition, que d'autres ateliers ont pu également appliquer plus tard.

Trois fragments présentaient des trous circulaires pratiqués avant ou après cuisson. On peut signaler que les pithari messéniens destinés au vin étaient souvent percés au foret (Blitzer, 1990, p. 686).

Les fonds sont plats ou annulaires et ces derniers constituent une caractéristique locale qui ne s'observe sur aucune autre production. Les trois quarts des fonds ont le dessous sablé, ce qui signifie que le fond, déjà façonné, était posé sur du sable avant de recevoir les colombins formant la paroi du vase, afin d'éviter qu'il ne se colle au support de fabrication. Des cordons de stabilisation sont parfois conservés au-dessus du plan de pose. Les diamètres des fonds varient entre $25 \mathrm{~cm}$ et $49 \mathrm{~cm}$. La majorité se situe entre $32 \mathrm{~cm}$ et $41 \mathrm{~cm}$, ce qui donne des pièces aux fonds particulièrement larges en comparaison avec les autres productions méridionales contemporaines.

La silhouette générale des pithoi biterrois ne peut être restituée avec certitude à cause de la grande fragmentation des pièces, mais la proposition de la figure $16 n^{\circ} 2$ n'est sans doute pas très éloignée de la réalité, ce que confirme un pithos presque entier trouvé à Ensérune et présentant la pâte caractéristique utilisée par cet atelier (fig. 18). 
En définitive, il n'y a pas de véritable standardisation pour ces récipients que les artisans réalisaient, certes, sur des bases communes dictées par la fonction, mais qu'ils finissaient tout de même avec une grande liberté et, peut-être aussi, selon la demande. C'est ce qui explique que les typologies proposées jusqu'à maintenant ne sont pas utiles par elles-mêmes, aux fins de la chronologie, et ne le sont pas davantage du point de vue typologique, puisqu'une pièce $d u V^{e} s$. av. J.-C. peut trouver un parallèle convaincant dans une autre du $\mathrm{I}^{\mathrm{er}} \mathrm{s}$.

L'analyse des productions en fonction des pâtes et des formes réalisées par les différents ateliers du Midi donnera, à terme, des résultats exploitables tant du point de vue de la typochronologie que de l'aire de diffusion d'un atelier donné. Autrement dit, ces recherches peuvent permettre de cerner le rayon d'action économique d'un centre producteur qui, à l'instar de ce qui s'observe pour Marseille et Béziers, correspond vraisemblablement à un établissement d'une certaine importance.

\section{LA DIFFUSION DE LA PRODUCTION}

Quant à la diffusion des pithoi biterrois présentant la pâte caractéristique décrite ci-dessus, on ne peut proposer qu'une vue préliminaire et forcément partielle appuyée sur le mobilier de quelques sites réellement examiné par l'un ou l'autre d'entre nous (fig. 19).

Dans la campagne de Béziers, la ferme de Casse-Diables à Sauvian (Hérault) a restitué un nombre élevé de pithoi (autour de $7 \%$ des fragments) dont $65 \%$ ont la pâte caractéristique utilisée par cet atelier.

Tous les fragments découverts sur l'habitat de hauteur de Mus à Murviel-lès-Béziers (Hérault), dans la vallée de l'Orb, ont également cette pâte.

Des pièces sont attestées à Ensérune (Nissan-lezEnsérune, Hérault), parmi lesquelles une est presque entière (fig. 18), sans que l'on puisse réellement les quantifier.

La Moulinasse à Salles-d'Aude (Aude) a également restitué des pièces biterroises mais il est, là aussi, impossible d'en évaluer l'occurrence statistique.

À Montlaurès (Narbonne, Aude), les fragments de pithoi de la phase 550-475 av. J.-C. sont rares, mais ils possèdent tous cette même pâte.

À Agde (Hérault), les pithoi sont rares pour toutes les époques de la ville grecque. Jusque vers 350 av. J.-C., ils présentent toujours cette pâte biterroise caractéristique.

Les fragments recueillis au Mont-Joui à Florensac (Hérault) (550-475 av. J.-C.) ont tous cette pâte.

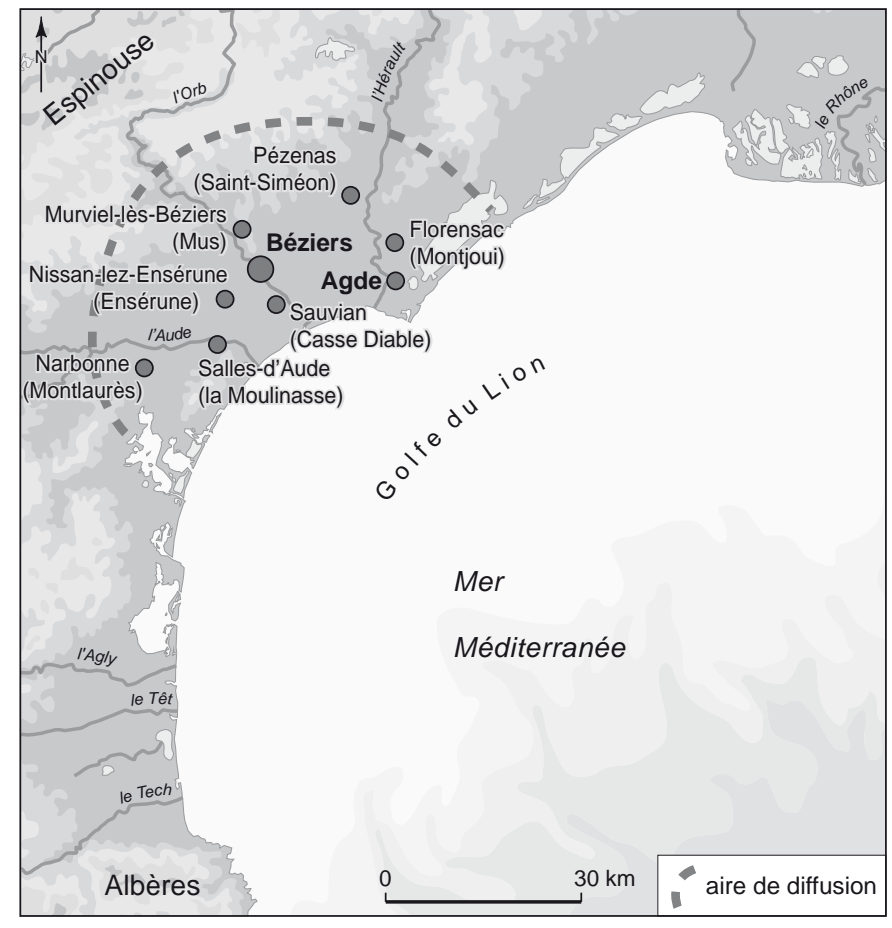

Fig. 19 - Carte de diffusion minimale des pithoi biterrois (DAO : C. Olive, SRA Languedoc-Roussillon).

À Saint-Siméon (Pézenas, Hérault), les pièces constituées de cette pâte sont également largement attestées.

Les pithoi de l'atelier de La Domitienne ont donc été distribués entre la basse vallée de l'Aude et la basse vallée de l'Hérault, sur une distance de 25-30 km à partir de Béziers, ce qu'il faut considérer comme une diffusion minimale.

\section{LE PITHOS}

\section{DESGRIPTION DU PITHOS}

$\mathrm{Au} v \mathrm{du}$ duangement de perspectives qu'apporte la découverte biterroise, il convient de revenir sur le pithos/ dolium, récipient souvent banalisé tant du point de vue technique que fonctionnel et qui est, en fait, révélateur d'un savoir-faire caractéristique d'un contexte culturel et de modes de production agricole, voire de conservation ou de transformation de certaines denrées alimentaires. Sa présence sur les sites méridionaux avant le $\mathrm{IV}^{\mathrm{e}} \mathrm{s}$. av. J.-C., époque à laquelle son emploi tend à se généraliser, peut alors fournir des indications d'une certaine importance.

C'est par le biais de la colonisation grecque que le pithos, ancêtre du dolium romain, a été introduit en Gaule 
et c'est sous l'appellation latine dolium/dolia que les grands vases de réserve et/ou de transformation des aliments ont été étudiés depuis près d'un siècle. Les premiers travaux sur la question concernaient déjà les pièces retrouvées en Languedoc occidental et, dès le début, on a remarqué que les pithoi anciens possèdent une pâte différente de celle des pièces des $\mathrm{IV}^{\mathrm{e}}$-III ${ }^{\mathrm{e}}$ s. av. J.-C., ces dernières différant à leur tour de celles du $\mathrm{I}^{\mathrm{er}}$ s. av. J.-C. (Coulouma, 1935, p. 536-539 ; Héléna, 1937, p. 297-310 ; Jannoray, 1955, p. 71 et p. 261-262).

Plus récemment, de nouvelles problématiques sont apparues, à commencer par la terminologie. Dans les années 1950, J. Jannoray constatait déjà que l'usage avait consacré le terme impropre de dolium pour les pièces antérieures aux $\mathrm{II}^{\mathrm{e}}$ s. av. J.-C. (Jannoray, 1955, p. 70, n. 1). Le terme pithos nous semble en effet préférable pour des raisons à la fois culturelles, chronologiques et typologiques (Ugolini et al., 1991, n. 32).

Pour les contextes de l'âge du Fer, les pithoi ont été généralement regroupés avec d'autres jarres plus ou moins grandes en céramique non tournée. Cela a généré une certaine confusion puisque le terme dolium a fini par désigner tout vase de grande taille. La conséquence la plus visible de cette pratique est apparue lorsque les archéologues ont commencé à compter les vases et fragments qu'ils découvraient. Grands vases non tournés et pithoi étant comptabilisés ensemble, l'occurrence réelle de ces derniers a été masquée par la masse des «vases de stockage ".

Il y a donc un problème de définition de l'objet lui-même, qu'il faut distinguer des jarres indigènes non tournées, tout simplement parce qu'il ne s'agit pas de la même classe céramique. Et puis, surtout à date ancienne et en regard des implications culturelles et commerciales que revêt l'apparition du pithos en Gaule, « acheter » ou « recevoir en cadeau » et utiliser un pithos n'a pas du tout le même sens que «fabriquer sur place " et utiliser un grand vase, bien que l'on puisse éventuellement se servir de la même manière de l'un comme de l'autre et bien que certaines jarres indigènes copient la forme du pithos.

Rarement trouvés entiers, les pithoi peuvent être de taille moyenne (hauteur supérieure à $50 \mathrm{~cm}$ ) jusqu'à très grande, ce dernier cas ne concernant jamais les jarres indigènes non tournées ; les pithoi sont faits à la main ou tournés, voire partiellement tournés ou juste finis au tour lent, détail technique qui, encore une fois, ne se retrouve pas sur les jarres indigènes ; ils ont des parois épaisses (plus de $1 \mathrm{~cm}$ ). Mais c'est surtout la pâte - caractérisée par une couleur rouge (ou beige, selon les productions) et un dégraissant sableux (et/ou micacé) de calibre relativement important qui permet de les distinguer des vases plus ou moins grands à pâte brun-noir de la tradition indigène.

La couleur est un critère facile à retenir. Elle implique qu'il y a au moins une différence dans le mode de cuisson. Il n'y a aucune raison de ne pas signaler ce détail pour les pithoi, alors qu'on le retient pour distinguer d'autres céramiques (par exemple, les pâtes claires et les grises monochromes), justement en fonction du mode de cuisson qui influe sur la couleur de la pâte.

Les exemplaires les plus anciens trouvés dans le Midi ont été considérés comme des importations (Garcia, 1987, p. 58-59) et on sait que Marseille en a produit dès la première moitié du VI ${ }^{\mathrm{e}}$ s. av. J.-C. (Villard, 1960, p. 63).

Les pithoi massaliètes et provençaux forment un ensemble qui peut être assez facilement identifié, même en l'absence d'ateliers archéologiquement attestés. On en trouve principalement le long des côtes à l'est du Rhône, jusque dans le Var. Ils appartiennent à au moins deux groupes distincts et sont caractérisés (entre autres) par une pâte de couleur beige rosé contenant un dégraissant composé de calcite et de quartzite broyés, ainsi que, dans la majorité des cas, de fines paillettes de mica. Ils présentent une bonne homogénéité de la pâte (Ratsimba, 2005).

En Languedoc-Roussillon, de la rive droite du Rhône jusqu'aux Pyrénées, les pithoi ont une pâte de couleur rougebrun et les compositions du dégraissant permettent de distinguer plusieurs groupes/ateliers formant « une famille de productions » différente de la précédente.

Dans le Gard et les plaines montpelliéraines, on distingue plusieurs groupes. En Languedoc occidental, trois productions sont ou peuvent être biterroises. Un autre groupe, d'apparition plus récente (après 350 av. J.-C.), est à situer dans l'Aude. Enfin, un dernier groupe était assez actif sur la côte du Roussillon (Ratsimba, 2005).

Il reste à déterminer si dans la basse vallée du Rhône (zone d'Arles et des Alpilles) ont existé d'autres ateliers ou si se croisent ici produits provençaux et produits languedociens.

Malgré l'existence d'un petit nombre de centres producteurs, géographiquement assez bien répartis, certains pithoi ont voyagé loin : par exemple, à Béziers, on trouve des pièces provençales et même des exemplaires qui sont courants en Languedoc oriental, alors qu'à Pech Maho a été mis au jour un fragment portant un nom grec incisé : EY $\Sigma[T]$ PATI $\Delta . .$. (Untermann, 1980, p. 326), qui pourrait indiquer une pièce importée de Provence sur ce site audois. 


\section{FONCTION DU PITHOS}

En Méditerranée orientale, le pithos était, selon les sources de l'époque homérique, destiné principalement aux denrées liquides ou semi-liquides : eau, huile, salaisons et surtout vin. Il pouvait toutefois recevoir des matières solides, comme c'est le cas du tribut payé en or et argent au roi Darius par ses sujets (Hérodote, Histoires, III, 96). Les métaux étaient d'abord fondus (ce qui les rendait à leur état liquide), puis versés dans des pithoi, que l'on cassait une fois le contenu durci pour récupérer le métal précieux et le refondre.

D'un autre côté, l'archéologie a fourni de multiples exemples, tant dans les mondes méditerranéens que chez les indigènes de la côte gauloise, de pithoi contenant des céréales, des fruits, de la vaisselle, etc., ce qui montre - à côté de la grande variabilité des tailles et des capacités - la polyvalence de ces grands vases, principalement utilisés pour les liquides, mais que l'on pouvait remplir de diverses autres choses.

Curieusement, dès les premiers travaux sur les grands vases de la Protohistoire méridionale, s'est imposée l'idée qu'en Gaule, avant la Conquête et l'apparition des chais romains, les dolia ont servi principalement au stockage des céréales (Tardieu, 1976). En partant du présupposé que ces grandes jarres étaient très répandues en milieu indigène, on en a fait quasiment le seul traceur (après les silos) de produits locaux - les céréales - susceptibles de représenter la contrepartie des importations méditerranéennes. Pour étayer cette hypothèse, les arguments suivants ont été mis en avant :

- certains dolia avaient un revêtement interne en torchis, rendant improbable leur utilisation pour stocker un liquide (Py, 1979) ;

- les exemplaires fêlés et réparés par des agrafes en plomb ne pouvaient pas contenir de liquides (Py, 1979) ;

- les dolia ont remplacé les silos pour les provisions alimentaires en général (Jannoray, 1955, p. 94 et p. 262) ;

- en Languedoc occidental, ils portent parfois des marques estampées représentant des épis de blé qui seraient l'image du contenu du récipient (Jannoray, 1955 ; Py, 1979) ;

- dans certains dolia, on a découvert des graines carbonisées (Py, 1979) ;

- l'augmentation progressive de leur capacité indique l'accroissement, constant dans le temps, de la production céréalière (Tardieu, 1976 ; Py, 1979 et 2001 ; Arcelin et al., 1982).

Ce dernier point a marqué le départ des recherches sur l'économie des indigènes, sur leur agriculture et sur le volume des surplus dégagés en tant que contrepartie des échanges avec leurs partenaires méditerranéens (Py, 1990 et 1993, p. 221 ; Garcia, 1987, 1992 et 1997).

L'étude des vases de stockage du Mont-Garou à Sanarysur-Mer (Var) a grandement conforté cette idée (Arcelin et al., 1982). En effet, en démontrant que la capacité de réserve avait augmenté au cours du $\mathrm{V}^{\mathrm{e}} \mathrm{s}$. av. J.-C., on mettait en évidence le développement agricole de la Gaule méridionale pendant ce siècle et la disponibilité accrue de surplus. De plus, les sources anciennes évoquaient la forte pénurie en blé qui frappait Athènes à la même époque. Marseille était alors vue comme l'intermédiaire idéal entre l'offre et la demande.

Mais d'autres travaux ont abouti à l'impossibilité de déterminer l'existence de stocks commercialisables à travers les récipients de réserve des milieux domestiques, comme au Plan de la Tour à Gailhan, dans le Gard (Dedet, 1987, p. 168), ou à l'île de Martigues, dans les Bouches-du-Rhône (Damotte, 2003), ou ont proposé qu'au moins une partie des pithoi ait servi à la vinification, comme à Coudounèu, Lançonde-Provence, dans les Bouches-du-Rhône (Verdin, 1996).

Ainsi ces recherches mettent l'accent sur le fait que l'emploi du pithos pour le seul stockage des céréales est loin d'être une évidence et cette utilisation reste même, globalement, très incertaine.

Si l'on évoque le cas de Marseille, point de départ de l'introduction du pithos en Gaule, on constate que le nombre de pièces attestées n'est pas très élevé : autour de $1 \%$ du total des vases (Gantès, 1992), auxquels s'ajoutent 18 exemplaires et 288 fragments provenant des fouilles du port (chantiers Jules-Verne et du Musée César, sous la direction de A. Hesnard, voir Ratsimba, 2005, p. 27), ce qui est peu au regard de l'ampleur de ces fouilles, et certainement d'autres pièces provenant de chantiers plus récents. Certains exemplaires étaient poissés : ils étaient donc au moins en partie employés pour la vinification, ce qui ne surprendra pas.

À Béziers, le nombre est plus important, entre $2 \%$ et $3 \%$ des vases. Ici aussi ont été relevées des traces de résine sur les parois internes (fig. 20) : au moins une partie de ces pithoi était donc réservée à la vinification.

On soulignera encore que seuls Marseille et Béziers ont livré des pithoi «anciens " de très grande dimension : diamètre de l'embouchure supérieur à $65 \mathrm{~cm}$ (Ratsimba, 2005, fig. 26 et 27).

Entre 600 et 400 av. J.-C., la diffusion du pithos (en pâte rouge ou beige) en milieu indigène est très limitée et très en dessous de certaines estimations ${ }^{13}$, quel que soit le mode de

13. Voir Garcia, 1997, p. 91 : « [...] les pithoi représenteront, au milieu du $\mathrm{V}^{\mathrm{e}}$ s. av. J.-C., 25 à $35 \%$ du mobilier sur les sites indigènes du Midi. " 




Fig. 20 - Fragments de pithoi biterrois en pâte de type I (issus de niveaux immergés fouillés sous la poste centrale à Béziers) avec traces du revêtement interne à base de résine. Pour comparaison, le fragment en haut à gauche présente l'extérieur du vase (cliché : C. Olive, SRA Languedoc-Roussillon).

comptage de ces grands récipients ${ }^{14}$. Parmi les exemplaires plus ou moins entiers mis au jour, environ la moitié avait une contenance inférieure à 75 litres (Ratsimba, 2005, p. 37 et p. 51, fig. 16-19). En d'autres termes, ces récipients étaient peu nombreux et aussi plutôt petits.

Les indices sur la fonction qu'ils ont remplie chez les indigènes proviennent essentiellement de sites détruits par le feu. Les pithoi y ont été retrouvés le plus souvent vides (en d'autres termes, ils contenaient une matière qui n'a pas laissé de traces), sauf deux qui conservaient des céréales : l'un, dont le fond était percé de neuf trous, au Plan de la Tour et, l'autre, à Coudounèu. Un troisième exemplaire brûlé contenait des restes de Vitis vinifera (à Coudounèu) et un tesson poissé a été retrouvé à Saint-Pierre-les-Martigues, commune de Martigues dans les Bouches-du-Rhône (Ratsimba, 2005, p. 52). On ajoutera à cette liste un pithos de Saint-Blaise à Saint-Mitre-les-Remparts, dans les Bouchesdu-Rhône (Bertucchi, 1992, fig. 95), dont l'inscription grecque indique son contenu : du vin «parfumé », doux (fig. 21).

14. Par exemple, à Lattes, l'augmentation concerne la première moitié du IV ${ }^{\mathrm{e}}$ s. et le nombre de fragments ne dépasse pas $5 \%$ du nombre total des fragments recueillis (Py, 2001, p. 1063).

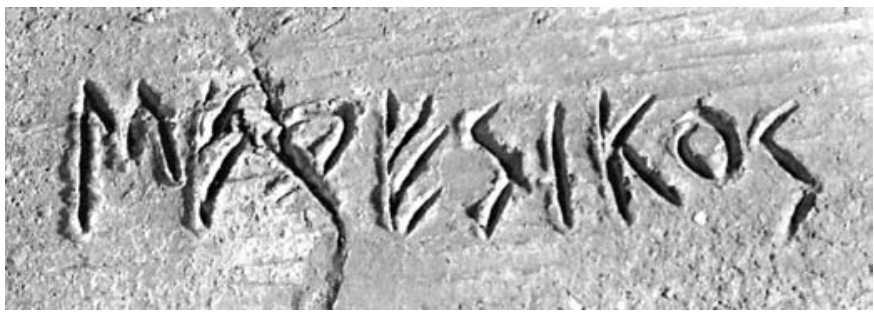

Fig. 21 - Fragment de pithos découvert à Saint-Blaise (Saint-Mitreles-Remparts, Bouches-du-Rhône) avec inscription avant cuisson en caractères grecs : "MFPESIKOS ", vin parfumé (d'après Bertucchi, 1992, fig. 95).

Une étude récente sur la place du pithos dans les maisons de la phase 2c (détruite vers 375-360 av. J.-C.) de l'̂̂le de Martigues a permis de se rendre compte que les pithoi, le plus souvent de petite taille, «ne sont nulle part nécessaires pour assurer ou même compléter la conservation des produits secs (céréales, légumineuses, fruits), alors qu'ils sont dans l'habitation gauloise les seuls objets de gros stockage capables de conserver les liquides " (Ratsimba, 2005, p. 36-48 et p. 53-55 ; Chausserie-Laprée, 2005, p. 179-183).

La généralisation de l'utilisation du pithos pourrait donc aller de pair avec l'essor de la viticulture indigène (Chausserie-Laprée, 2005, p. 181). C'est ce que suggéreraient les restes de fruits, de pédoncules, de rafles et de pépins observés dans certains dolia (Île de Martigues et Coudounèu). Il est toutefois certain qu'après la vinification le vin ne peut rester dans les mêmes récipients sans devenir rapidement du vinaigre et il faut avoir recours à d'autres vases pour la conservation du produit fini. On peut également penser à l'oléiculture et aux besoins de réserves qu'elle a pu induire.

Toutefois, dans ce contexte, on rappellera que le pithos est parfois associé à des meules ou contenait des graines carbonisées (Plan de la Tour, le Marduel à Saint-Bonnetdu-Gard et Île de Martigues) : l'analyse des grains a montré qu'il s'agissait d'orge (qui est la céréale dominante, par exemple au Plan de la Tour), et non de blé. Cela peut être l'indice de la fabrication de bière, boisson alcoolisée à base d'orge particulièrement répandue, consommée déjà bien avant l'introduction du vin en Gaule et étrangement oubliée par la recherche (Ratsimba, 2005, p. 54-56 ; ChausserieLaprée, 2005, p. 183). Le pithos a donc pu servir aussi à contenir de la bière.

Enfin, l'eau faisait partie des réserves d'une maison et la seule constante dans la répartition des pithoi dans le village de l'Île de Martigues était la présence, quasi systématique, 
d'un exemplaire de petite taille vraisemblablement dévolu à cette fonction.

On pensera également au fait que de nombreux habitats étaient établis en des lieux où l'accès à l'eau potable n'était pas aisé. C'est le cas des sites établis au bord de lagunes à l'eau saumâtre ou salée, ou encore de ceux qui occupaient des hauteurs éloignées des sources ou des fleuves. Le stockage de l'eau y était donc nécessaire et le pithos pouvait répondre à cette fonction assurée plus tard par les citernes.

Globalement, les données archéologiques recueillies sur les sites indigènes plaident donc en faveur d'une utilisation du pithos plutôt pour la conservation des liquides, même si on a pu, parfois, l'employer pour le grain. L'association du pithos et des céréales est donc toute relative pour la Protohistoire méridionale et on peut ajouter d'autres arguments.

Il est improbable que les dolia aient remplacé les silos. Il est même évident que, sur certains sites (Ensérune, Ruscino ), les deux étaient en service en même temps et vraisemblablement pour des usages différents, car silo et dolium n'offrent pas les mêmes possibilités de conservation. On ne s'en sert pas de la même façon et donc l'un n'est pas l'alternative de l'autre.

On a proposé d'établir une relation entre les marques figurant des épis de blé estampés sur certains dolia et le contenu de ces vases, des céréales. Mais que faut-il penser alors du contenu des jarres marquées d'un élément architectural (chapiteau/colonne, voir par ex. Jannoray, 1955, pl. LIV.2 et LXXI.5), d'animaux, d'étoiles, ou même d'une figure anthropomorphe (par ex. Jannoray, 1955, pl. LIV.1). Il est sans doute plus raisonnable de voir dans ces timbres des marques d'ateliers ou d'artisans potiers travaillant au sein d'un atelier ${ }^{15}$.

Les réparations au plomb des exemplaires fendus ont été interprétées comme symptomatiques de l'impossibilité d'y stocker des liquides. Mais que penser alors des nombreux dolia pareillement réparés dans les chais romains ? Ne faut-il pas plutôt envisager que le revêtement résineux rendait étanche la paroi endommagée et que le récipient pouvait être réutilisé pour le vin ou tout autre liquide?

À cela il faut ajouter la notion de l'investissement économique que représentait l'achat d'un pithos, qui coûtait cher (voir par exemple, dans le monde grec, Amyx, 1958).

15. On tiendra compte aussi du fait que le phénomène des timbres doliaires est relativement récent. Aucun site n'a livré, jusqu'ici, de telles marques dans des contextes assurément antérieurs à la fin du IV $^{\mathrm{e}}$ s. av. J.-C.
L'observation des pâtes a révélé que les centres de production n'étaient pas très nombreux dans le Midi et la découverte du four à Béziers montre que la fabrication se faisait dans des structures adaptées, ce que laissaient déjà entendre quelques textes anciens (Géoponiques, VI, 3, § 14 ; Julius Pollux, Onomastikon, VII, 164).

La difficulté et le très haut degré de technicité nécessaire à la réalisation d'un pithos étaient même proverbiaux (Hésychios, Lexique, s. v. pithos ; Julius Pollux, Onomastikon, VII, 163). La comparaison avec des productions modernes confirme l'étendue du savoir-faire nécessaire à la fabrication de ces produits. On imagine aisément ce que représente la manipulation d'un vase pouvant nécessiter $80 \mathrm{~kg}$ d'argile, voire plus, et l'adresse du potier qui place des boudins pouvant peser $5 \mathrm{~kg}$ à $8 \mathrm{~kg}$ chacun, selon la technique du colombin étiré (Gouin, Vogt, 2002). Le temps nécessaire à la fabrication est connu par la production subactuelle des pithari messéniens (Grèce continentale) (Blitzer, 1990). Entre chaque colombin, le potier respectait un délai de séchage d'une journée. Selon la taille de la pièce, le montage demandait jusqu'à 20 jours, le séchage entre 8 jours et 20 jours ; puis l'enfournement, la cuisson, le refroidissement et le défournement plusieurs jours supplémentaires. Il fallait donc compter au moins un mois pour terminer un pithos; mais bien évidemment on en fabriquait plusieurs en même temps.

Traditionnellement les fours à pithoi sont plutôt de forme ronde et ne sont pas très grands pour des raisons économiques, car, si la cuisson est ratée, on perd un nombre limité de vases. Encore récemment, une fournée ne comptait pas plus de dix ou douze vases et le maintien de la température consommait une cinquantaine de fagots de branchages divers de $50 \mathrm{~kg}$ chacun. Le refroidissement était une étape délicate qu'il fallait surveiller pour éviter que les vases ne se fissurent et, d'après les estimations, dans les meilleurs des cas, $5 \%$ à $10 \%$ des vases étaient tout de même cassés ou ratés durant leur cuisson (Gouin, Vogt, 2002).

Recherche, acheminement et préparation de l'argile et du dégraissant, montage, séchage, approvisionnement en combustible, cuisson, refroidissement et défournement, la fabrication exigeait un grand savoir-faire, beaucoup de temps et de place et une quantité considérable de matières premières. Le lieu où se déroulait la chaîne opératoire devait être proche des ressources (argile, dégraissants, eau, combustible) et proche d'une voie de circulation pour l'acheminement des matières premières comme des produits finis. 
En regard de ces contraintes et des coûts de production, il est évident que le prix de vente était élevé et l'achat d'un pithos ne se justifiait que pour un besoin qui n'était pas celui de gérer les réserves de céréales, ce que l'on pouvait faire de manière beaucoup plus économique et plus efficace avec d'autres moyens. Et cela sans compter qu'il est difficile de croire que l'on ait pu conserver les surplus destinés à la vente dans les pièces à vivre des maisons.

$$
\text { * } *
$$

On sait depuis plusieurs années que Béziers a été un important centre de production céramique durant l'âge du Fer et que c'est dans le Biterrois qu'ont été découverts les ateliers les plus anciens du Languedoc-Roussillon ${ }^{16}$.

Les deux ateliers mis au jour sur la commune de Béziers (place de la Madeleine et ZAC de la Domitienne) ont des caractéristiques techniques particulièrement évoluées (Ugolini, à paraître a) et ne représentent certainement qu'une infime partie de ceux qui ont existé et se sont succédé durant près de trois siècles. On attribue au premier diverses classes de céramique tournée (grise monochrome, à pâte claire, de cuisine) et au second une production de pithoi, mais les potiers locaux ont produit aussi des mortiers (Gomez, 2000), des tuiles (qui sont, après celles de Marseille, les plus anciennes du Midi, voir Olive, Ugolini, 1997 ; Chazelles, 2006a), des poids de métiers à tisser, parfois tournés (qui sont, avec ceux de Marseille, les plus anciens du Midi, voir Chazelles, 2000 et 2006b), des lampes (Ugolini, Olive dir., 2006 ; Ugolini, à paraître b) ainsi que des terres cuites décorées à usage vraisemblablement votif (Gomez, Ugolini, 2006).

Béziers donne ainsi l'image d'un site quasiment autosuffisant du point de vue de la céramique et de la terre cuite, ce qui confère à la ville une place à part dans le cadre du Languedoc-Roussillon contemporain et même du Midi, avec Marseille.

Le four de potier de La Domitienne n'a pas d'équivalent, à notre connaissance, pour la même fonction et pour la même époque autour du bassin méditerranéen. On peut toutefois établir une comparaison avec un four à amphores mis au jour à Marseille (Rothé, Tréziny, 2005, p. 471, fig. 519) (fig. 22, $\mathrm{n}^{\mathrm{o}} 1$ ). Contemporain du four de Béziers, sa structure est plus grande, mais on y retrouve l'emploi de

16. On rappellera les deux fours de potier mis au jour au Mas de Pascal à Aspiran (Hérault), lors des travaux de l'A75. Isolés dans la campagne, ils ont produit de la céramique grise monochrome autour de 500 av. J.-C. (fouilles de A. Pezin, Inrap, voir Demoule dir., 2004, p. 115 , fig. à gauche). l'adobe, les piliers latéraux, le principe des fausses voûtes et même, dans l'état b2, le mur-pilier central partageant en deux la chambre de chauffe.

Quant à la forme générale, la comparaison avec les fours à pithoi qui fonctionnaient en Crète, il y a tout juste quelques décennies (fig. 22, no 3), permet de voir que l'exemple biterrois en est très proche. Enfin, pour l'époque romaine, la production des dolia, dans un pays fortement viticole comme l'était le Biterrois, était une nécessité qui a été amplifiée par le changement d'échelle de la viticulture. Un atelier du Haut-Empire a été fouillé à Saint-Bézard (Aspiran, Hérault, voir Mauné et al., 2005, fig. p. 120). Bien que structurellement différent du four de Béziers et beaucoup plus grand (on pouvait y cuire au moins une vingtaine de grands dolia), il confirme que, à toutes époques, la production s'est faite dans des ateliers spécialisés et que les fours étaient adaptés à la taille comme au nombre des vases.

Ainsi, l'atelier de La Domitienne s'inscrit dans une tradition méditerranéenne plusieurs fois millénaire et sa production est précisément identifiée, ce qui est un cas unique pour l'âge du Fer.

L'idée ancienne de potiers itinérants fabriquant sur place des pièces à la demande paraît donc aujourd'hui dépassée, même si l'on ne peut totalement exclure que des artisans aient pu parfois mettre en place un atelier près d'un site donné à l'occasion d'une grosse commande. Cela semble tout de même improbable entre le $\mathrm{VI}^{\mathrm{e}} \mathrm{s}$. et la fin $\mathrm{du}$ $\mathrm{IV}^{\mathrm{e}} \mathrm{s}$. av. J.-C., lorsque les pithoi ne sont pas très nombreux et que les ateliers restent rares.

Si tous n'ont pas été identifiés et précisément localisés, Marseille a sans doute joué un rôle de premier plan, notamment en Provence. Il est vraisemblable que d'autres ateliers que ceux de Béziers et Marseille aient distribué des pièces de bonne qualité : on en suppose l'existence notamment autour de l'étang de Berre et en Roussillon (Ratsimba, 2005). Dans tous les cas, c'est à partir des lieux de production que les pithoi étaient acheminés vers des sites récepteurs.

La découverte de l'atelier biterrois a été aussi l'occasion d'un renouvellement de la problématique liée à l'usage des pithoi en Gaule méridionale, que l'on avait restreint au stockage des céréales, alors que cette fonction pouvait être assurée de façon beaucoup plus simple et moins onéreuse que par l'achat de tels récipients. Il faut désormais envisager l'emploi des pithoi pour la conservation et la transformation de produits liquides comme le vin (lorsqu'on relève un revêtement résineux, ce qui est rare) et l'eau, mais aussi, de façon plus inattendue, la bière. Le pithos doit être 
considéré comme un conteneur polyvalent qui pouvait recevoir liquides et solides. Toutefois, son achat, qui constituait un investissement important, était motivé par un besoin qui n'était certainement pas, au départ, la conservation céréalière.

Les pithoi ne sont quasiment pas attestés sur les sites d'Ibérie antérieurs à la romanisation, même grecs, puisqu'ils sont absents des niveaux contemporains d'Emporion et
Rhodè. Leur présence en Méditerranée occidentale reste donc une caractéristique forte du Midi, ce que l'on sait depuis plusieurs décennies (Héléna, 1937, p. 297-310). Elle y témoigne de la pénétration rapide et essentiellement côtière d'une pratique émanant d'une implantation grecque importante qui a stimulé l'apparition d'ateliers spécialisés proposant un conteneur à liquides performant et pouvant aussi s'adapter à d'autres usages.
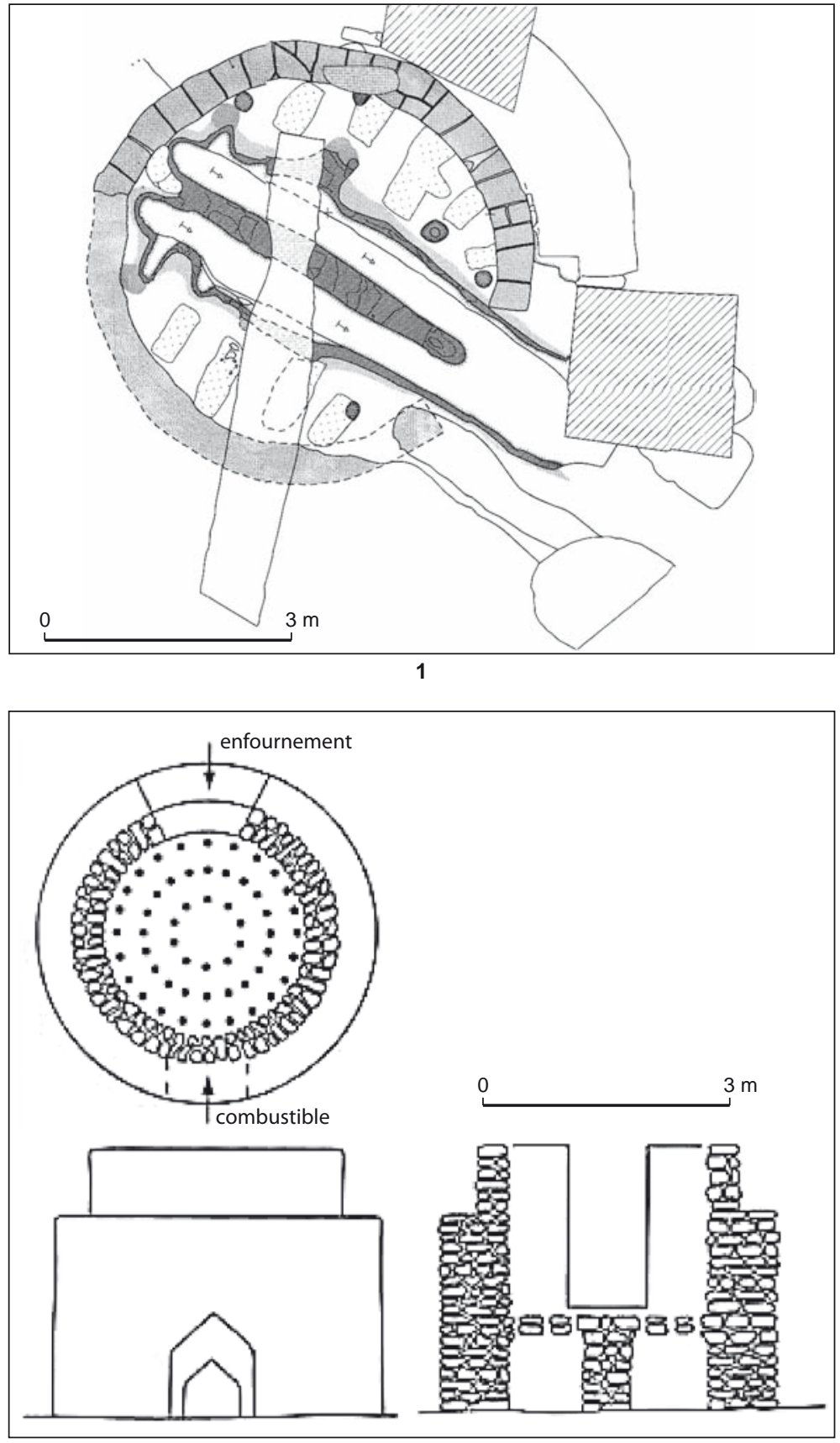

3

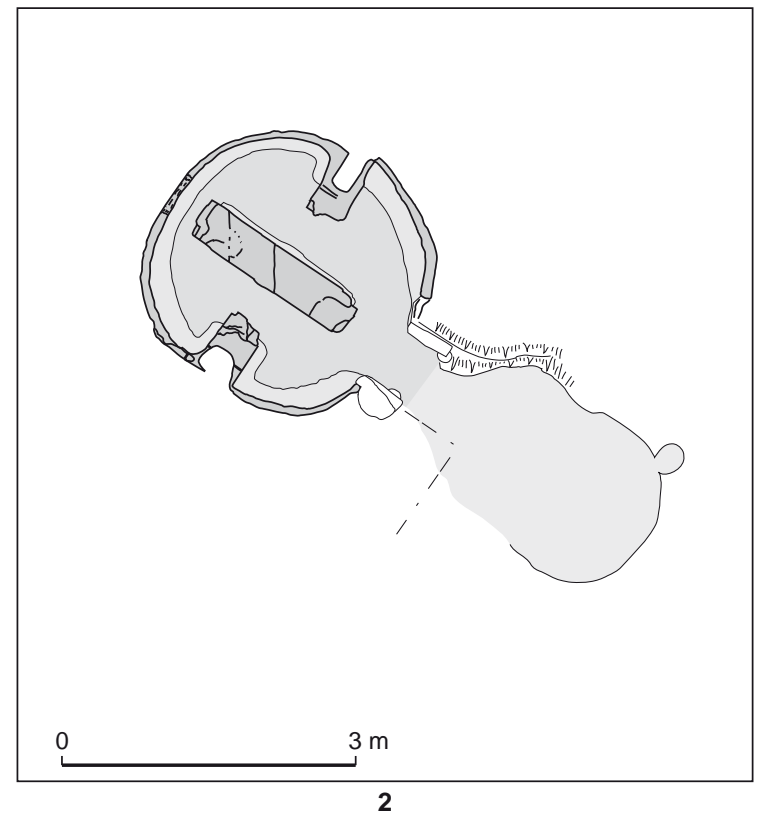

Fig. 22 - Comparaison de fours : 1, four à amphores de la rue Leca à Marseille, daté du Ve s. av. J.-C. (FR 5179phase II, état b2) (d'après Rothé, Tréziny, 2005, fig. 519); 2, four à pithoi de la ZAC de la Domitienne à Béziers, daté de la fin $d u V I^{e}-I V^{e}$ s. av. J.-C. ; 3, four à pithoi de Margaritès en Crète, daté $d u X^{e}$ s. (d'après Gouin, Vogt, 2002, fig. 8). 


\section{BIBLIOGRAPHIE}

\begin{tabular}{ll}
\multicolumn{1}{c}{ ABRÉVIATIONS } \\
AFAN & Association pour les fouilles archéologiques nationales. \\
AFEAF & Association française pour l'étude de l'âge du Fer. \\
ARALO & Association pour la recherche archéologique en Languedoc oriental. \\
BEFAR & Bibliothèques des Écoles françaises d'Athènes et de Rome. \\
$B S R$ & Bilan scientifique régional. \\
DAM & Documents d'archéologie méridionale. \\
DFS & Document final de synthèse. \\
INRAP & Institut national de recherches archéologiques préventives. \\
RAN & Revue archéologique de Narbonnaise.
\end{tabular}

SOURCES ANTIQUES

\section{GÉOPONIQUES}

Géoponika : Agricultural Pursuits, VI, traduit du grec par T. Owen, imprimé à compte d'auteur, Londres, 1805-1806.

\section{HÉRODOTE}

Histoires, III, texte établi et traduit par P.-E. Legrand, Paris, Les Belles Lettres (coll. CUF), 1967.

\section{HÉSYCHIOS D'ALEXANDRIE}

Lexicon, texte établi et traduit par M. Schmidt, Iéna, 1861.

\section{Julius Pollux}

Onomastikon, VI-X, texte établi et traduit par E. Bethe, fasc. 2, Stuttgart, B. G. Teubner, 1931 (réimpr. 1967).

\section{BIBLIOGRAPHIE GÉNÉRALE}

AMYX D. A.

1958 : « The Attic stelai -III- Vases and others containers ", Hesperia, 27, p. 164-310.

\section{ARCElin P., ArCelin-Pradelle C.,} GASCO Y.

1982 : « Le village protohistorique du MontGarou, Sanary, Var », DAM, 5, p. 53-137.

\section{BERTUCCHI G.}

1992 : Les Amphores et le vin de Marseille, $V I^{e}$ s. av. J.-C.-II s. apr. J.-C., Paris, CNRS Éditions (coll. Suppl. à la $R A N, 25)$, $250 \mathrm{p}$.

\section{BLITZER H.}

1990 : « Storage-jar production and trade in the traditional Aegean », Hesperia, 59-4, p. $675-711$

\section{CHAUSSERIE-LAPRÉE J.}

2005 : Martigues : terre gauloise entre Celtique et Méditerranée, Paris, éd. Errance, 255 p.

ChaZelles C.-A. DE

2000 : «Éléments archéologiques liés au traitement des fibres textiles en Languedoc occidental et Roussillon $\mathrm{au}$ cours de la Protohistoire $\left(\mathrm{VI}^{\mathrm{e}}-\mathrm{I}^{\mathrm{er}} \mathrm{s}\right.$. av. n. è.) ", in CARDON D., FEUGÈRE M (DIR.), Archéologie des textiles, des origines au $V^{e}$ s., Actes du colloque de Lattes, oct. 1999, Montagnac, Monique Mergoi (coll. Monographies Instrumentum, 14), p. 115-130.

2006a : « Les tuiles de couverture », in Ugolini D., Olive C. (DIR.), Béziers I (600-300 av. J.-C.) : la naissance de la ville, Béziers, éd. Musée du Biterrois, p. 56-57.

2006b : " La fabrication des textiles ", in Ugolini D., Olive C. (DIR.), Béziers (600-300 av. J.-C.) : la naissance de la ville, Béziers, éd. Musée du Biterrois, p. 64-66.

\section{Coulouma J.}

1935 : « Magalas et son oppidum de Montfo", in Actes du congrès préhistorique de France, XI $I^{e}$ session, Périgueux, 1934, Paris, Société préhistorique française, p. 518-556.

DAMOTTE L.

2003 : « Mobilier céramique et faciès culturel de l'habitat gaulois de l'Île de Martigues", $D A M, 26$, p. 171-234.

\section{DEDET B.}

1987 : Habitat et vie quotidienne en Languedoc au milieu de l'âge du Fer : l'unité domestique $n^{\circ} 1$ de Gailhan, Gard, Paris, éd. du CNRS (coll. Suppl. à la RAN, 17).

DEMOULE J.-P. (DIR.)

2004 : La France archéologique : vingt ans d'aménagements et de découvertes, Paris, Hazan.

\section{GANTÈS L.-F.}

1992 : « L'apport des fouilles récentes à l'étude quantitative de l'économie massaliète ", in Marseille grecque et la Gaule, Lattes/Aix-en-Provence, éd. ADAM/ Univ. de Provence (coll. Travaux du Centre Camille-Jullian, 11 ; Études massaliètes, 3), p. 171-178.

\section{GARCIA D.}

1987 : "Observations sur la production et le commerce des céréales en Languedoc méditerranéen durant l'âge du Fer : les 
formes de stockage des grains ", RAN, 20, p. 43-98.

1992 : «Du grain et du vin : à propos des structures de stockage de l'agglomération portuaire de Lattes ", in PY M. (DIR.), Recherches sur l'économie vivrière des Lattarenses, Lattes, éd. ARALO (coll. Lattara, 5), p. 165-182.

1997 : « Les structures de conservation des céréales en Méditerranée nord-occidentale au premier millénaire av. J.-C. », in MeEKS D., GARCIA D. (DIR.), Techniques et économies antiques et médiévales : le temps de linnovation, Paris, éd. Errance, p. 88-95.

\section{GOMEZ É.}

2000 : «Contribution à l'étude des mortiers de cuisine : les mortiers du Languedoc occidental du $\mathrm{VI}^{\mathrm{e}}$ au $\mathrm{IV}^{\mathrm{e}}$ s. av. J.-C. ", $D A M, 23$, p. 113-143.

Gomez É. avec la collab. de CASSIGNOL J., FICHES I.

2004 : La Domitienne à Béziers, DFS, Service archéologique de la ville de Béziers.

\section{GOMEZ É., UGOLINI D.}

2006 : «Des terres cuites votives », in Ugolini D., Olive C. (DIR.), Béziers I (600-300 av. J.-C.) : la naissance de la ville, Béziers, éd. Musée du Biterrois, p. 67-69.

Gouin P., VogT C.

2002 : «Les pithoi de Margaritès (Crète) : techniques et culture ", La Céruse, 38, mars 2002 et mis en ligne le 11 juillet 2006, consulté en janvier 2008 : http:// tc.revues.org/document1084.html

\section{HÉLÉNA P.}

1937 : Les Origines de Narbonne, ToulouseParis, éd. Privat-Didier, 489 p.

JANDOT C.

2000 : «Béziers, ZAC de la Domitienne », BSR du Languedoc-Roussillon 2000, p. 117-118.

\section{JANDOT C. $E T A L$.}

2000 : ZAC de la Domitienne à Béziers (Hérault) : occupations du Néolithique ancien, Néolithique final, Vérazien, de la Protohistoire, de l'Antiquité et d'époque moderne, DFS de diagnostic archéologique, AFAN.

JANDOT C., GOMEZ É. avec la collab. de JUng C., Kotarba J., Olive C.

2003 : RD 28 à Béziers (Hérault) : nouvelles observations sur la voie Domitienne à l'est de Béziers, Rapport final d'opération, diagnostic archéologique, Inrap.
JANNORAY J.

1955 : Ensérune : contribution à l'étude des civilisations préromaines de la Gaule méridionale, Paris, De Boccard (coll. BEFAR, 181), 490 p., 71 pl.

Mauné S., Bourgaut R., LeSGURe J., DURAND B. avec la collab. de Santran C., Garrato G., Silvéréano S., MARCHAND G., SAVAY-GUERRAZ H.

2005 : «Aspiran, Dourbie et Saint-Bézard », BSR du Languedoc-Roussillon 2005, p. 117-121.

\section{MAZière F., Olive C., UGOLINI D.}

2001 : «Esquisse du territoire de Béziers $\left(\mathrm{VI}^{\mathrm{e}}-\mathrm{IV}^{\mathrm{e}}\right.$ s. av. J.-C.) », in MARTIN ORTEga A., Plana Mallart R. (DIR.), Territori politic i territori rural durant l'edat del Ferro a la Mediterrània occidental, Actes de la table ronde internationale d'Ullastret (E), 25-27 mai 2000, Girona, Museu d'arqueologia de Catalunya-Ullastret (coll. Monografies d'Ullastret, 2), p. 87-114.

\section{Olive C.}

1995 : «Les découvertes récentes à Béziers dans leur contexte archéologique ", in Clavel-LévêQUe M., Plana MALLART R. (DIR.), Cité et territoire, Actes du $1^{e r}$ colloque européen de Béziers, 14-16 nov. 1994, Paris, Les Belles Lettres (coll. Annales littéraires de l'Université de Besançon, 565), p. 207-216.

\section{Olive C., UgOLINI D.}

1997 : « La Maison 1 de Béziers et son environnement ( $\mathrm{V}^{\mathrm{e}}-\mathrm{IV} \mathrm{e}^{\mathrm{e}} \mathrm{s}$. av. J.-C.) », in UGOLINI D. (DIR.), Languedoc occidental protohistorique : fouilles et recherches récentes, $V I^{e}-I V^{e}$ s. av. J.-C., Aix-en-Provence, Publications de l'Université de Provence (coll. Travaux du Centre Camille-Jullian, $19)$, p. $87-129$.

\section{Olive C., UGOlini D., JANDOT C.,}

\section{WIÉGANT J.-P.}

2001 : «Béziers : le four de potier de la Domitienne ", BSR du LanguedocRoussillon 2001, p. 125-126.

PY M.

1979 : «Agriculture et artisanat : l'essor économique du $\mathrm{III}^{\mathrm{e}}$ au I $\mathrm{I}^{\mathrm{er}} \mathrm{s}$. ", Les Dossiers de l'Archéologie, 35, p. 86-98.

1990 : Culture, économie et société protohistoriques dans la région nîmoise, Rome, École française de Rome (coll. École française de Rome, 131), 2 vol., 957 p.

1993 : Les Gaulois du Midi : de la fin de l'âge du Bronze à la conquête romaine, Poitiers, Hachette, 288 p.
2001 : " Doliums ", in PY M., ADROHER AurouX A.-M., SANCHEZ C. (DIR.), Dicocer $^{2}$, Corpus des céramiques de l'âge du Fer de Lattes (fouilles 1963-1999), Lattes, ARALO (coll. Lattara, 14), p. 1063-1086.

\section{RATSIMBA A.}

2002 : Les Pithoi de Béziers : analyse d'une production et première approche de sa diffusion $\left(V I^{e}-I V^{e}\right.$ s. av. J.-C.), Mémoire de maîtrise en archéologie, Université d'Aix-Marseille-I, Aix-en-Provence, 90 p.

2005: LePithos en Gauleméridionale:production, diffusion et utilisation d'un mobilier d'origine grecque ( $V I^{e}-I V^{e}$ s. av. J.-C.), Mémoire de Master 2 en histoire, Université d'AixMarseille-I, Aix-en-Provence.

2006 : "Les pithoi biterrois ", in UGOLINI D., Olive C. (DIR.), Béziers I (600-300 av. J.-C.) : la naissance de la ville, Béziers, éd. Musée du Biterrois, p. 98-102.

\section{ROTHÉ M.-P., TRÉZINY H.}

2005 : Marseille et ses alentours, Paris, Académie des inscriptions et belles-lettres (coll. Carte archéologique de la Gaule, 13-3).

\section{TARDIEU J.-P.}

1976 : Recherches sur les "dolia" dans le Midi de la Gaule (VI ${ }^{e}$ s. av. J.-C./II ${ }^{\text {er }}$ s. apr. J.-C.), Mémoire de maîtrise d'histoire ancienne, Université Aix-en-Provence, 2 vol., 122 p. et $98 \mathrm{pl}$.

\section{UGOLINI D.}

2000 : «Consommer les aliments : boire, cuire et manger en Languedoc-Roussillon au cours de l'âge du Fer ", in BuxÒ R., PONS E. (DIR.), Els productes alimentaris d'origen vegetal a l'edat del Ferro de l'Europa occidental : de la producciò al consum, Actes du XXII colloque de l'AFEAF, Girona (E), 21-24 mai 1998, Girona, Museu d'arqueologia de Catalunya (coll. Sèrie Monogràfica, 18), p. $389-400$.

2002 : " La céramique à cuire d'Agde $\left(\mathrm{VI}^{\mathrm{e}}-\mathrm{II}^{\mathrm{e}}\right.$ s. av. J.-C. ", in Repas des vivants et nourriture pour les morts en Gaule, Actes du XXV colloque de l'AFEAF, CharlevilleMézières, 24-27 mai 2001, Reims (coll. Mémoires de la Société archéologique champenoise, 16 ; suppl. au Bulletin $\mathrm{n}^{\circ} 1$ ), p. 191-200.

2003 : "Céramique de cuisine tournée ", in LANDES C. (DIR.), Les Étrusques en France : archéologie et collections, Catalogue de l'exposition de Lattes, sept. 2002-janv. 2003, Lattes, éd. IMAGO-Musée de Lattes, p. 156-158.

2005 : "Les Ibères des Pyrénées au Rhône : bilan de 20 ans de recherches ", in Mon Ibéric als països catalans : homenatge a Josep Barberà $i$ Farràs, Actes du XIII coll.loqui 
internacional d'arqueologìa de Puigcerdà (E), 14-15 nov. 2003, Puigcerdà, éd. Institut d'Estudis Ceretans, vol. I, p. 165-202.

À paraître a : «De la vaisselle au matériau de construction : techniques et emplois de la terre cuite en tant que traceur culturel en Languedoc-Roussillon ", in Grecs et indigènes de la Catalogne à la mer Noire, Actes de la $5^{e}$ réunion de l'atelier du programme européen Ramses, Naples, Centre Jean-Bérard, 29-30 oct. 2007.

À paraître b : " Les lampes grecques du Languedoc-Roussillon antérieures au $\mathrm{III}^{\mathrm{e}}$ s. av. J.-C. ", in Archéologie et histoire de l'éclairage en Gaule, de la Préhistoire au début du Moyen Âge, Actes de la $2^{e}$ table ronde de l'International Lamps Association, Millau, 22-24 mars 2007

\section{UGOLINI D., OLIVE C.}

1987-1988 : «Un four de potier du $\mathrm{V}^{\mathrm{e}} \mathrm{s}$. av. J.-C. à Béziers, place de la Madeleine », Gallia, 45, p. 13-28.

2006 : «De l'arrivée à la consommation : l'impact des trafics et des produits étrusques en Languedoc ", in Gli
Etruschi da Genova ad Ampurias, Atti del $X X I V^{\circ}$ convegno di Studi etruschi ed italici, Marseille-Lattes, 26 sett.-1 ott. 2002, PisaRoma, Istituti editoriali e poligrafici internazionali, vol. II, p. 555-581.

2009 : « Sites grecs, sites indigènes : essai sur le fonctionnement des habitats de l'Hérault occidental (VI ${ }^{\mathrm{e}}-\mathrm{IV}^{\mathrm{e}} \mathrm{s}$. av. J.-C.) ", in Habitats et paysages ruraux en Gaule et regards sur d'autres régions du monde celtique, Actes du XXXI colloque international de l'AFEAF, Chauvigny, 17-20 mai 2007, t. II, Chauvigny, Association des publications chauvinoises, p. 215-243.

UGOLINI D., OLIVE C. (DIR.)

2006 : Béziers I (600-300 av. J.-C.) : la naissance de la ville, Béziers, éd. Musée du Biterrois, $150 \mathrm{p}$.

\section{Ugolini D., Olive C., Marchand G.,}

Columeau $P$.

1991 : «Un ensemble représentatif du $\mathrm{V}^{\mathrm{e}} \mathrm{s}$. av. J.-C. à Béziers, place de la Madeleine, et essai de caractérisation du site ", $D A M$, 14, p. 141-203.

\section{Ugolini D., PeZin A.}

1993 : « Un aperçu sur le mobilier du $\mathrm{V}^{\mathrm{e}} \mathrm{s}$. av. J.-C. en Languedoc occidental et en Roussillon ", in CHAZELLES C.-A. DE (DIR.), " Contribution au problème ibérique dans l'Empordà et en Languedoc », DAM, 16, p. 80-87.

\section{UNTERMANN J.}

1980 : Monumenta Linguarum Hispanicarum -II- Die Inschriften in iberischer Schrift aus Südfrankreich, Wiesbaden, Ludwig Reichert Verlag.

VERDIN F. avec la collab. de BRIEN-

Poitevin F., Chabal L., Marinval P., Provansal M.

1996-1997 : « Coudounèu (Lançon-deProvence, Bouches-du-Rhône) : une ferme-grenier et son terroir au $\mathrm{V}^{\mathrm{e}} \mathrm{s}$. av. J.-C. », DAM, 19-20, p. 165-198.

\section{VILLARD F.}

1960 : La Céramique grecque de Marseille $\left(V I^{e}-I V^{e} s.\right)$ : essai d'histoire économique, Paris, De Boccard (coll. BEFAR, 195), 178 p. 